\title{
Circumpolar patterns of Arctic freshwater fish biodiversity: A baseline for monitoring
}

\author{
Sarah M. Laske ${ }^{1}$ (D) | Per-Arne Amundsen ${ }^{2}$ | Kirsten S. Christoffersen ${ }^{3}$ | \\ Jaakko Erkinaro $^{4}$ | Guðni Guðbergsson ${ }^{5}$ | Brian Hayden ${ }^{6}$ (D) | Jani Heino ${ }^{7}$ (D) | \\ Kerstin Holmgren $^{8}$ | Kimmo K. Kahilainen9 ${ }^{9}$ Jennifer Lento ${ }^{6}$ (D) | Panu Orell ${ }^{4}$ | \\ Johan Östergren $^{8}$ | Michael Power ${ }^{10}$ | Ruslan Rafikov ${ }^{11}$ | Atso Romakkaniemi ${ }^{4}$ | \\ Martin-A. Svenning ${ }^{12}$ (D) | Heidi Swanson ${ }^{10}$ | \\ Matthew Whitman ${ }^{13}$ | Christian E. Zimmerman ${ }^{1}$
}

\author{
${ }^{1}$ Alaska Science Center, US Geological \\ Survey, Anchorage, Alaska \\ ${ }^{2}$ Department of Arctic and Marine Biology, \\ Faculty of Biosciences, Fisheries and \\ Economics, UiT The Arctic University of \\ Norway, Tromsø, Norway \\ ${ }^{3}$ Freshwater Biological Laboratory, \\ Department of Biology, University of \\ Copenhagen, Copenhagen, Denmark \\ ${ }^{4}$ Natural Resources Institute Finland, Oulu, \\ Finland \\ ${ }^{5}$ Marine and Freshwater Research Institute, \\ Reykjavík, Iceland \\ ${ }^{6}$ Canadian Rivers Institute, University of \\ New Brunswick, Fredericton, NB, Canada \\ ${ }^{7}$ Freshwater Centre, Finnish Environment \\ Institute, Oulu, Finland \\ ${ }^{8}$ Department of Aquatic Resources, Institute \\ of Freshwater Research, Swedish University \\ of Agricultural Sciences, Drottningholm, \\ Sweden \\ ${ }^{9}$ Department of Forestry and Wildlife \\ Management, Inland Norway University of \\ Applied Sciences, Evenstad, Norway \\ ${ }^{10}$ Department of Biology, University of \\ Waterloo, Waterloo, ON, Canada \\ ${ }^{11}$ Institute of Biology of Komi Science Center \\ of the Ural Branch of the Russian Academy \\ of Sciences, Yekaterinburg, Russia \\ ${ }^{12}$ Arctic Ecology Department, Fram Center, \\ Norwegian Institute for Nature Research \\ (NINA), Tromsø, Norway
}

\section{Abstract}

1. Climate change, biological invasions, and anthropogenic disturbance pose a threat to the biodiversity and function of Arctic freshwater ecosystems. Understanding potential changes in fish species distribution and richness is necessary, given the great importance of fish to the function of freshwater ecosystems and as a resource to humans. However, information gaps limit large-scale studies and our ability to determine patterns and trends in space and time. This study takes the first step in determining circumpolar patterns of fish species richness and composition, which provides a baseline to improve both monitoring and conservation of Arctic freshwater biodiversity.

2. Information on species presence/absence was gathered from the Circumpolar Biodiversity Monitoring Program's Freshwater Database and used to examine patterns of freshwater fish $\gamma^{-}, \alpha$, and $\beta$-diversity across $234^{\circ}$ of longitude in the Arctic. The metrics of diversity provided information on species richness and composition across hydrobasins, ecoregions, and Arctic zones.

3. Circumpolar patterns of fish species biodiversity varied with latitude, isolation, and coarse ecoregion characteristics; patterns were consistent with historic and contemporary barriers to colonisation and environmental characteristics. Gammadiversity was lower in the high Arctic compared to lower latitude zones, but $\alpha$ diversity did not decrease with increasing latitude below $71^{\circ} \mathrm{N}$, reflecting glacial history. Alpha-diversity was reduced to a single species, Arctic charr Salvelinus alpinus, in ecoregions above $71^{\circ} \mathrm{N}$, where $\gamma$-diversity was the lowest. Beta-diversity indicated little variation in the composition and richness of species across the High

[Correction added on 13 September 2021, after first online publication: The copyright line was changed.]

This is an open access article under the terms of the Creative Commons Attribution-NonCommercial-NoDerivs License, which permits use and distribution in any medium, provided the original work is properly cited, the use is non-commercial and no modifications or adaptations are made.

(c) 2019 The Authors. Freshwater Biology published by John Wiley \& Sons Ltd. This article has been contributed to by US Government employees and their work is in the public domain in the USA. 
${ }^{13}$ US Bureau of Land Management,

Fairbanks, Alaska

\section{Correspondence}

Sarah M. Laske, Alaska Science Center, US Geological Survey, Anchorage, AK, USA.

Email: slaske@usgs.gov

Funding information

Academy of Finland, Grant/Award

Number: (1140903, 1268566); Swedish

Environmental Protection Agency;

Norwegian Research Council, Grant/Award

Number: (183984, 186320, 213610); Danish

Environmental Agency; Ministry of Science

and Higher Education (Russia), Grant/Award

Number: (AAAA-A17-117112850235-2)
Arctic; at lower latitudes, ecoregions contained more species, although species composition turned over across large spatial extents.

4. In an analysis of five ecoregions in the circumpolar Arctic, physical isolation, and ecoregion area and topography were identified as strong drivers of $\gamma^{-}, \alpha-$, and $\beta$-diversity. Physical isolation reduced the $\gamma$ - and $\alpha$-diversity, and changes in $\beta$ diversity between adjacent locations were due mainly to losses in species richness, rather than due to differences in species composition. Heterogeneity of habitats, environmental gradients, and geographic distance probably contributed to patterns of fish dissimilarity within and across ecoregions.

5. This study presents the first analysis of large-scale patterns of freshwater fish biodiversity in the circumpolar Arctic. However, information gaps in space, time, and among taxonomic groups remain. Future inclusion of extensive archive and new data will allow future studies to test for changes and drivers of the observed patterns of biodiversity. This is important given the potential impacts of ongoing and accelerating climate change, land use, and biotic exchange on Arctic fish biodiversity.

\section{KEYWORDS}

$\beta$-diversity, dissimilarity, distribution, richness, spatial scale

\section{1 | INTRODUCTION}

Global environmental change threatens the biodiversity and function of all ecosystems (Sala et al., 2000), and Arctic ecosystems are no exception (Meltofte, 2013). Maintenance of freshwater biodiversity is crucial to the healthy function of Arctic ecosystems and to the preservation of ecosystem services provided to humans (Culp et al., 2012; Socolar, Gilroy, Kunin, \& Edwards, 2016; Wrona et al., 2013). However, Arctic freshwater ecosystems are vulnerable to multiple global and localised stressors, including climate warming, biological invasions, and direct anthropogenic disturbance (Rolls et al., 2018; Wrona et al., 2013). Scenario analyses of changing biodiversity show that Arctic ecosystems are currently overwhelmingly influenced by climate change when compared to other factors (e.g. land use, biotic exchange, carbon dioxide, and nitrogen deposition), but this may change as global economic interests increase in Arctic regions (Hovelsrud, Poppel, van Oort, \& Reist, 2011; Huntington et al., 2007). The effects of each of these stressors alone and in combination, although often difficult to determine (Hayden, Myllykangas, Rolls, \& Kahilainen, 2017; Schindler \& Smol, 2006; Wrona et al., 2006), may impact the fishes living in Arctic streams and lakes. Ongoing and future changes in climate and land use will probably have profound effects on fish biodiversity (Rolls et al., 2018; Wrona et al., 2006).

Understanding potential changes to fish species distribution and richness is highly relevant to monitoring and conservation efforts because of the importance of fish to humans (Berkes \& Jolly, 2002; $\mathrm{Hu}$, Laird, \& Chan, 2017) and because fish contribute to the structure and function of Arctic aquatic food webs (Eloranta et al., 2015;
Reist et al., 2006; Thomas, Harrod, Hayden, Malinen, \& Kahilainen, 2017; Wrona et al., 2006). Large information gaps exist, however, in our knowledge of Arctic freshwater fish distribution and ecology, and patchy collections of species data limit relevant studies on largescale biodiversity, compromising the ability of managers to assess patterns and trends in biodiversity (Christiansen et al., 2013; Comte, Buisson, Daufresne, \& Grenouillet, 2013; Stendera et al., 2012). However, understanding the relationship between locally collected data and regional biodiversity patterns is critical for effective and efficient conservation and monitoring of Arctic freshwater fish (Kraft et al., 2011; Leprieur et al., 2011; Socolar et al., 2016).

Fish biodiversity is affected by landscape factors that act at multiple spatial and temporal scales (Hewitt, 2000; Poff, 1997; Tonn, 1990). Species distribution, richness, and compositional patterns are controlled by both contemporary and historic environmental features of climate, geology, and morphometry (Dias et al., 2014; Hugueny, Oberdorff, \& Tedescco, 2010). Compositional change is often strongly influenced by isolating variables (April, Hanner, DionCôté, \& Bernatchez, 2013; Leprieur et al., 2011; Mangerud et al., 2004) such as glacial retreat and development, which are responsible for many of the distribution patterns influencing present-day biodiversity. Interestingly, increased dispersal between paleo-connected drainage basins during the last glacial maximum has resulted in higher present-day compositional similarity for regions that were historically linked (Dias et al., 2014). Strong dispersal abilities and migratory life histories also promoted rapid recolonisation in deglaciated regions in Europe and North America (e.g. Fennoscandia and northeast Canada), which support the current broad geographic 
distribution of cold-water salmonids (April et al., 2013; Christiansen et al., 2013; Griffiths, 2006, 2010; Koljonen, Jansson, Paaver, Vasin, $\&$ Koskiniemi, 1999).

Dispersal processes and opportunities are an important factor in the geographic distribution and spatial patterns of $\gamma$-diversity (i.e. regional species richness), $\alpha$-diversity (i.e. local species richness), and $\beta$-diversity (i.e. variation in species composition among locations) in Arctic freshwater fishes (Dias et al., 2014; Heino, 2011). Fish communities should be less similar at greater geographic distances because of changes in species identity along broad spatial gradients (Abell et al., 2008; Anderson et al., 2011; Beisner, PeresNeto, Lindström, Barnett, \& Longhi, 2006; Soininen, McDonald, \& Hillebrand, 2007). When communities are not identical, all similarity patterns can be described using two processes-species replacement and loss (Baselga, 2010). These components of $\beta$-diversity are commonly referred to as species turnover and nestedness (Baselga, 2010; Koleff, Gaston, \& Lennon, 2003). Turnover is the replacement of some species by others along a spatial or environmental gradient, while nestedness refers to a non-random loss (or disaggregation) of species from the richest locality (Baselga, 2010).

Understanding the processes that govern $\beta$-diversity is important for determining the mechanisms responsible for maintaining biodiversity (Baselga, 2010; Socolar et al., 2016). However, $\beta$-diversity patterns are complicated by spatial heterogeneity and spatial extent (Heino, 2011; Leprieur et al., 2011); accordingly, if community comparisons are made across a wide geographic region (e.g. the circumpolar Arctic), spatially structured variation in species composition should be greater than environmental controls (Heino, 2011; Kraft et al., 2011). That is, large-scale effects of continental drift, orogeny, and glaciation would have more influence over patterns in $\beta$-diversity than local-scale factors such as habitat area, resource availability, or biotic interactions.

Beta-diversity studies, which rely on numerous local-scale community investigations (i.e. $\alpha$-diversity studies), provide a method for scaling up local patterns to improve management and conservation of regional or continental species biodiversity (i.e. $\gamma$-diversity) (Leprieur et al., 2011; Socolar et al., 2016). At continental scales, studies of Arctic fish species diversity show similar patterns of species richness radiating outwards from historic glacial refugia, which results in a general decline in species richness to the north and west on both the North American and European continents (Griffiths, 2006, 2010). According to the Arctic Biodiversity Assessment, however, large-scale studies of fish diversity across latitudinal and longitudinal gradients in the Arctic are lacking (Christiansen et al., 2013). The current collection of species richness assessments (e.g. Griffiths, 2006, 2010) and compositional lists (e.g. Christiansen et al., 2013) are valuable, but they do not sufficiently address spatial patterns of $\alpha$ - and $\beta$-diversity in fishes across the circumpolar Arctic.

This study provides a baseline for future monitoring efforts recommended by the Arctic Biodiversity Assessment (CAFF, 2013). Our aim was to evaluate biodiversity patterns in freshwater fish species for the circumpolar Arctic in an effort to determine $\gamma^{-}, \alpha$-, and $\beta$ diversity patterns that will help to guide future monitoring plans.
First, we focused on broad scales, and evaluated patterns across the spatial extent of available data. We hypothesised that there would be a decline in fish species richness with increasing latitude, so we predicted that both $\gamma$ - and $\alpha$-diversity would decline with latitude, and that $\alpha$-diversity would depend on $\gamma$-diversity. We further hypothesised that variation in species composition would decline at higher latitudes, where species richness is expected to be lower, and that variation in species composition would increase with distance between locations. We therefore predicted that $\beta$-diversity would decline with latitude, and increase with increasing distance between locations.

Given that species richness and compositional patterns are often controlled by contemporary and historic environmental features, we hypothesised that $\alpha$-, $\beta$-, and $\gamma$-diversity would differ among regions with differing characteristics. We also hypothesised that location and geography would affect regional and local richness, and that reduced regional species richness in isolated and mountainous areas would also limit local richness. Relying on ecoregions with robust data sets, we predicted that $\gamma$ - and $\alpha$-diversity would be lower or species composition would differ for ecoregions of higher elevation (i.e. mountain regions) relative to low-elevation regions. We also predicted that $\gamma$ - and $\alpha$-diversity would be lower for isolated ecoregions (i.e. islands) compared to connected ecoregions (i.e. mainland). Finally, we hypothesised that $\beta$-diversity would differ regionally and that variation would arise from both change in species richness and composition.

\section{2 | METHODS}

\section{1 | Study area}

Ecologically, the circumpolar Arctic often refers to all of the land north of the treeline (Meltofte, 2013). The region is characterised by short, cool summers with periods of 24-hr sunlight that vary in duration depending on latitude. Summer marks a short, intense period of productivity in Arctic aquatic ecosystems (Rautio et al., 2011). Conversely, winters are long and cold with periods of polar darkness, and this seasonal reduction in resources limits species persistence and may ultimately act as a critical determinant of community composition (Hayden, Harrod, Sonninen, \& Kahilainen, 2015; Shuter, Finstad, Helland, Zweimüller, \& Hölker, 2012). Much of the terrestrial environment is underlain by permafrost. Freshwater habitats are varied, ranging from small streams to large rivers, and including small thermokarst ponds and large lakes (Wrona et al., 2013). For the purpose of this paper, we considered the circumpolar Arctic as the area bounded by the subarctic boundary, $60^{\circ} \mathrm{N}$ latitude, or the Conservation of Arctic Flora and Fauna (CAFF) boundary, for the most inclusive data set (Meltofte, 2013). Collected fish data spanned $234^{\circ}$ longitude, from Alaska across the northern Atlantic to western Siberia, and covered $23^{\circ}$ of latitude, which includes the high Arctic, low Arctic, and subarctic (Meltofte, 2013; Figure 1a). 


\section{2 | Data processing}

We extracted fish data from 3,168 stations where the assemblage of fish was assessed (Table S1), rather than surveys focused on single species or commercial fishing. Fish data originated from national monitoring databases, government data reports, academic research programmes, and industry monitoring programmes (see data sources in the Arctic Biodiversity Data Service; abds.is). Sixty-seven percent of stations were lotic $(n=2,111)$ and $33 \%$ lentic $(n=1,057)$. In some instances, multiple stations occurred within a single river or lake because multiple studies were conducted in the same waterbody, or because multiple stations were included within the sampling design of the single study (e.g. longitudinal stations along upstreamdownstream river gradients). Data from broadly selective gear types (e.g. electrofisher or fyke net) or multiple gears that sampled different components of the assemblage (e.g. hook and line, minnow traps, and gill nets) were used. Because data were collected by different sampling methods across stations, we converted all data to presence/absence to avoid false inferences about abundance that could reflect methodological bias. We included all stations that sampled fish using multiple-mesh gill nets because they are commonly used for monitoring (Appelberg, 2000; CEN, 2015); however, we acknowledge that some small-bodied fishes (e.g. Gasterosteidae) are not vulnerable to capture by gill nets and that false absences may occur for small-bodied fishes at some stations. When sampling occurred over multiple years, all recorded presences were consolidated, and species presence/absence was recorded as a binary indicator: present (1) or absent (0). We acknowledge that this approach may obscure temporal changes in species diversity for the $32 \%$ of stations that were sampled more than once (Table S1).

Stations were assigned to hierarchical landscape groupings that provided spatial context for analysis. At the largest, circumpolar Arctic scale, stations occurred in one of four latitudinal zones-the three Arctic zones (Meltofte, 2013) and an additional boreal zone that allowed us to retain all stations south of the predefined Arctic zones (Figure 1). At a regional scale, stations were classified by ecoregion according to the Terrestrial Ecoregions of the World (TEOW; Olson et al., 2001) classification, which defines global ecoregions based on distinct assemblages and environmental conditions, including climate. Terrestrial ecoregions in the Arctic are related to climatic conditions and provide the necessary connection between landscape features (e.g. geology, temperature, precipitation) and the freshwater ecosystem. TEOWs are smaller than the flow-based Freshwater Ecoregions of the World (Abell et al., 2008), which allow a more (a)

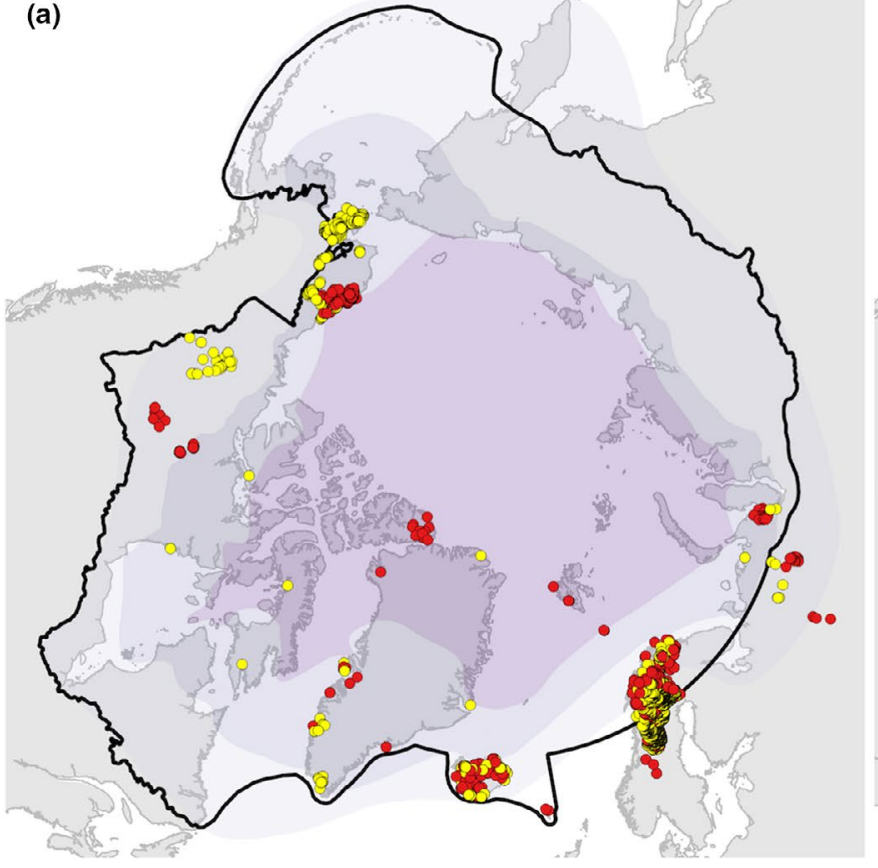

(b)

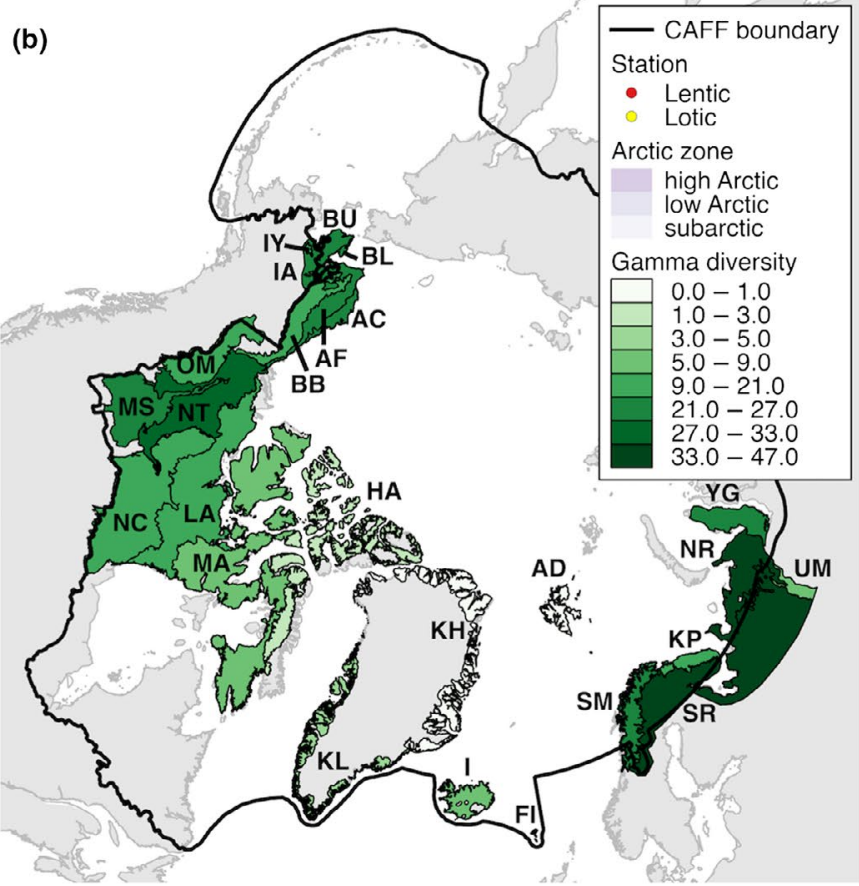

FIGURE 1 Distribution of lentic and lotic stations included in the analysis of Arctic freshwater fish biodiversity (a) and the $\gamma$-diversity of ecoregions, as quantified by estimates of species richness from reference texts (Mecklenburg et al., 2002; Muus \& Dahlström, 1993; Ponomarev, 2017; Scott \& Crossman, 1973) and expert knowledge (b). The black line indicates the Conservation of Arctic Flora and Fauna (CAFF) boundary of the Arctic. Ecoregions are BU, Beringia Upland Tundra; BL, Beringia Lowland Tundra; IY, Interior Yukon-Alaska Alpine Tundra; IA, Interior Alaska-Yukon Lowland Tundra; AF, Arctic Foothills Tundra; AC, Arctic Coastal Tundra; BB, Brooks-British Range Tundra; NT, Northwest Territories Taiga; OM, Ogilvie-Mackenzie Alpine Tundra; LA, Low Arctic Tundra; MS, Muskwa-Slave Lake Forests; MA, Middle Arctic Tundra; HA, High Arctic Tundra; NC, Northern Canadian Shield Taiga; KH, Kalaallit Nunaat High Arctic Tundra; KL, Kalaallit Nunaat Low Arctic Tundra; I, Iceland Birch Forests and Alpine Tundra; FI, Faroe Islands Boreal Grasslands; AD, Arctic Desert; SM, Scandinavian Montane Birch Forest; SR, Scandinavian and Russian Taiga; KP, Kola Peninsula Tundra; RT, Northwest Russian-Novaya Zemlya Tundra; UM, Ural Montane Forests and Tundra; and YG, Yamal-Gydan Tundra 
detailed view of how geography may influence diversity. For example, five TEOW, including the Arctic Desert [Svalbard], Kola Peninsula Tundra, Scandinavian and Russian Taiga, Scandinavian Montane Birch Forest, and Northwest Russian-Novaya Zemlya Tundra, exist within the Barents Sea Drainages Freshwater Ecoregion, yet each of these TEOW has unique landscapes factors that influence freshwater biota (e.g. climate, geology, elevation; Poff, 1997; Tonn, 1990). At a local scale, stations were grouped into hydrobasins, which are global catchments that are derived using a standard approach at different spatial scales (Lehner \& Grill, 2013). Hydrobasin scales range from level 01, which is at the continent scale, to level 12 at the smallest sub-basin scale. Stations were classified for small-scale spatial analysis based on the intersection of level 07 hydrobasins (mid-scale sub-basins) and Arctic TEOW (level 07 hydrobasin $\times$ TEOW intersection, hereafter, hydrobasins), to ensure grouping based on both drainage basin and climatic conditions (Figure S1). All station classifications (zone, ecoregion, and hydrobasin) were assigned using geographic information systems (ArcGIS version 10.3, Esri, Redlands, CA, U.S.A.).

\section{3 | Circumpolar diversity}

Over the spatial extent of the gathered data, we assessed the total number and identities of fish species from literature and expert knowledge (Christiansen et al., 2013; Mecklenburg, Mecklenburg, \& Thorsteinson, 2002; Muus \& Dahlström, 1993; Ponomarev, 2017; Scott \& Crossman, 1973). We determined the number and identities of species in the Arctic (high and low zones), the subarctic, and in the ecoregions with sampled stations. We acknowledge that intraspecific diversity is common in Arctic regions (e.g. Siwertsson et al., 2010; Woods et al., 2012); however, it was not considered in this analysis. Species found in each of the individual ecoregions represent the regional species pool or $\gamma$-diversity of that ecoregion.

Alpha-diversity was calculated by averaging species richness of each station within the hydrobasin boundary $\left(\alpha_{\text {basin }}=\bar{\alpha}_{\text {station; }}\right.$; Whittaker, 1972). With the hydrobasin as our unit of interest, we included both lentic and lotic communities in our estimates of $\alpha$ diversity. We found that this was appropriate-to include fishes from both ecosystem types in a single diversity analyses-given the large spatial scale of the study, and the added benefit of preserving sample sizes within ecoregions. Mean $\alpha$-diversity of ecoregions was determined, and we assessed relationships between $\alpha$-diversity and hydrobasin area, between $\alpha$-diversity and latitude (hydrobasin centroid), and between $\alpha$-diversity and ecoregion $\gamma$-diversity using leastsquares linear regression. Model parameters were log-transformed when necessary to meet assumptions of the analyses.

Beta-diversity (i.e. the variation in species composition among/ between sites) and its turnover and nestedness components were determined across latitudinal zones and ecoregions using dissimilarity matrices (betapart, R package version 1.5.0; Baselga, Orme, Villeger, De Bortoli, \& Leprieur, 2018). Total $\beta$-diversity, calculated as $\beta_{\text {sor }}$, the Sørensen dissimilarity index (Baselga, 2010), encompasses both spatial turnover and differences in species richness (Koleff et al., 2003). It can be broken into component parts of turnover $\left(\beta_{\text {sim }}\right)$, and nestedness $\left(\beta_{\text {nes }}\right)$, given the additive relationship: $\beta_{\text {sor }}=\beta_{\text {sim }}+\beta_{\text {nes }}$, where $\beta_{\text {sim }}$ is the Simpson dissimilarity index and $\beta_{\text {nes }}$ is the nestedness-resultant dissimilarity (Baselga, 2010; Lennon, Koleff, Greenwood, \& Gaston, 2001). A value of one for total $\beta$ diversity indicates there that are no species in common between a pair of sites, whereas a value of zero indicates that all of the species are shared between sites.

In each ecoregion and latitudinal zone (boreal, subarctic, low Arctic, and high Arctic), we calculated $\beta$-diversity using multiple-site dissimilarities. Multiple-site dissimilarity calculations $\left(\beta_{\mathrm{SOR}}, \beta_{\mathrm{SIM}}\right.$, and $\beta_{\mathrm{NES}}$ ) allowed us to quantify the heterogeneity of species composition across all stations within a hydrobasin, because $\beta$-diversity depends on species co-occurrence patterns across all sampled locations (Baselga, 2013). Using hydrobasin estimates of $\beta_{\mathrm{SOR}}, \beta_{\mathrm{SIM}}$, and $\beta_{\mathrm{NES}}$, we were able to estimate the mean values and standard deviation of $\beta$-diversity components across hydrobasins within an ecoregion and zone. Because we wished to include as many hydrobasins as possible in the analysis, $\beta$-diversity differences among ecoregions and between zones could not be directly compared due to differences in sample sizes (i.e. unequal number of stations), which influences richness data (Gotelli \& Colwell, 2001). Therefore, we limit discussion of multiple-site dissimilarity to whether turnover or nestedness contributed equally to total $\beta$-diversity; differences between $\beta_{\text {SIM }}$ and $\beta_{\text {NES }}$ were determined using two-tailed, paired Student's t-tests (R package version 3.4.1).

In each ecoregion and latitudinal zone, we calculated $\beta$-diversity using pairwise dissimilarities of hydrobasins. Pairwise dissimilarities allowed us to examine spatial patterns in diversity and correlations between geographic distance and total $\beta$-diversity, turnover, and nestedness. Pairwise dissimilarities $\left(\beta_{\text {sor }}, \beta_{\text {sim }}\right.$, and $\left.\beta_{\text {nes }}\right)$ were calculated from species presence/absence matrices, with species arranged in columns and sites (i.e. hydrobasin identifiers) in rows. Beta-diversity dissimilarity matrices were modelled as a function of pairwise spatial distances between hydrobasins using Mantel tests (vegan, R package version 2.4-6; Oksanen et al., 2018), after deriving pairwise distances between hydrobasin centroids (geosphere, $\mathrm{R}$ package version 1.5-7; Hijmans, 2017).

\section{4 | Regional diversity comparisons}

In Alaska, Iceland, and Fennoscandia (i.e. Finland, Norway, and Sweden), data collected from the CBMP-freshwater database were sufficiently robust to permit a direct comparative analysis of $\gamma^{-}, \alpha$, and $\beta$-diversity among individual ecoregions. We used data from five ecoregions: Arctic Coastal Tundra, Brooks-British Range Tundra, Iceland Boreal Birch Forest and Alpine Tundra, Scandinavian and Russian Taiga (Fennoscandia only; stations west of $30.8^{\circ} \mathrm{E}$ longitude), and Scandinavian Montane Birch Forest and Grasslands. Gammadiversity (i.e. the regional species pool) was determined using the data available in the database, rather than extracting information 
from the literature. This provided an accurate assessment of species encountered in the hydrobasins where sampling took place, rather than inferring from published range distribution maps.

Estimates of $\gamma$-diversity were standardised for comparison among ecoregions by using sample-based rarefaction to determine the number of species $\left(S_{\text {rare }}\right)$ at the lowest common sample size within the subset of ecoregions. Data at the sample level (within stations) were used for this analysis to increase the number of samples used in this analysis and improve accuracy of diversity estimates. Individual sampling events at each station were used in randomisation tests that compared sample-based rarefaction curves (rareNMtests, R package version 1.1; Cayuela \& Gotelli, 2014). Comparisons of $\gamma$-diversity across adjacent ecoregions (e.g. in Alaska) were based on the ecological null hypothesis from Cayuela, Gotelli, and Colwell (2015) that two or more samples were drawn randomly from the same species pool; any differences in species composition or richness would be minimal and the result of random chance or rare species. Comparisons of $\gamma$-diversity across continents (e.g. Arctic Coastal Tundra in Alaska to Scandinavian and Russian Taiga in Fennoscandia) were made based on the biogeographical null hypothesis from Cayuela et al. (2015) that two or more samples were drawn from assemblages that share species richness profiles (i.e. species accumulation curves are the same); species richness would be similar even if species composition differs.

We calculated $\alpha$-diversity (species richness at the hydrobasin scale) and $\beta$-diversity in all hydrobasins with 10 or more stations. Using sample-based rarefaction (rareNMtests, $r$ package version 1.1; Cayuela \& Gotelli, 2014), we determined $\alpha$-diversity $\left(\alpha_{\text {rare }}\right)$ as the number of species encountered at 10 stations in each hydrobasin. The mean $\alpha_{\text {rare }}$ was calculated and compared across ecoregions using an analysis of variance (ANOVA) with a post hoc pairwise t-test comparison using a false discovery rate (FDR) correction. We determined ecoregion total $\beta$-diversity and its component parts of turnover and nestedness using multiple-site dissimilarity calculations ( $\beta_{\mathrm{SOR}}, \beta_{\mathrm{SIM}}$, and $\beta_{\text {NES }}$ ) by randomly resampling $(n=100)$ the data from a subset of 10 stations in each hydrobasin (betapart, R package version 1.5.0; Baselga et al., 2018; Baselga \& Orme, 2012). Randomly resampling 10 stations (standardising the number of sites) allowed us to make comparisons of $\beta$-diversity across ecoregions. Hydrobasin means of $\beta_{\mathrm{SOR}}, \beta_{\mathrm{SIM}}$, and $\beta_{\mathrm{NES}}$ were determined for each ecoregion and compared among ecoregions using analysis of variance (ANOVA) with a post hoc pairwise $t$-test comparison using a FDR correction. We also determined which component of $\beta$-diversity was underlying the patterns found in each ecoregion by using a paired, one-tailed $t$-test for each ecoregion to compare average values of $\beta_{\mathrm{SIM}}$ and $\beta_{\mathrm{NES}}$.

\section{3 | RESULTS}

\section{1 | Circumpolar diversity}

Station distribution was not uniform across the sampled area (Figure 1a), with large differences in the number of stations sampled among the 25 ecoregions (median $=8$ stations, range $=2-1,385$ stations; Table S1); the majority of stations included in the database were found in Alaska, Iceland, and Fennoscandia (included in regional diversity analysis, below). Based on data collection, literature, and expert knowledge, we found that $\gamma$-diversity varied from one to 47 species, with lower richness in high latitude ecoregions (e.g. High Arctic Tundra and Kalaallit Nunaat High Arctic Tundra) and on islands of the north Atlantic Ocean (e.g. Arctic Desert and Iceland Boreal Birch Forests and Alpine Tundra; Figure 1b). In total, we identified 100 fish species that represented 16 families in the study region; the composition of species turned over across the longitudinal gradient (Figure 2; Table S2); with 29 species occurring only in North America and 50 species occurring only in Fennoscandia and Russia. Seventeen species (families: Anguillidae, Esocidae, Gadidae, Gasterosteidae, Osmeridae, and Salmonidae) occur across continents; four salmonid species were introduced from North America to Iceland, Fennoscandia, or Russia (Table S2). In Greenland, Iceland, and on other islands of the North Atlantic, only 10 species occur, and six of these species occur in other regions. The majority of species $(n=77)$ occur as far north as the high and low Arctic zones, while 23 (11 Cyprinidae) occur only in subarctic or boreal zones below the low Arctic boundary. Of the 100 fish species known to the study area, only 56 appeared in the CBMP database and were included in the biodiversity analyses presented in this paper (Table S2)

Using only presence/absence records from the database, we determined whether $\alpha$-diversity was related to area, latitude, and $\gamma$ diversity. Log-transformed $\alpha$-diversity was unrelated to hydrobasin area (slope $=-1.00 \times 10^{-5} \pm 5.09 \times 10^{-6}$, intercept $=0.89 \pm 0.05$, $r^{2}=0.01, d f=287, p=0.05$ ), and it did not steadily decline with latitude (Figure 3a). There was, however, an abrupt loss in $\alpha$-diversity at latitudes above $70.7^{\circ} \mathrm{N}$, where records indicated that Arctic charr Salvelinus alpinus was the only species present. Below $70.7^{\circ} \mathrm{N}$, the log-transformed $\alpha$-diversity increased slightly with latitude (slope $=0.06 \pm 0.01$, intercept $=-3.08 \pm 0.99, r^{2}=0.05, d f=285$, $p<0.001$ ), which translated to an average $\alpha$-diversity increase of 1.3 species over $10^{\circ}$ of latitude (from $60^{\circ}$ to $70^{\circ} \mathrm{N}$ ). Log-transformed $\alpha$-diversity increased with $\gamma$-diversity (slope $=0.03 \pm 2.57 \times 10^{-3}$, intercept $=0.15 \pm 0.06, r^{2}=0.37, d f=296, p<0.001$; Figure 3b). Therefore, in high latitude ecoregions with low $\gamma$-diversity (e.g. Arctic Desert, High Arctic Tundra, and Kalaallit Nunaat High Arctic Tundra; Figure $1 b$ ), $\alpha$-diversity was also low (Table 1). Little variation in $\alpha$ diversity occurred among low $\gamma$-diversity ecoregions $(\gamma \leq 5)$, where $\alpha$-diversity increased 0.13 species given a four species increase in $\gamma$-diversity. However, in ecoregions with higher $\gamma$-diversity $(\gamma \geq 43)$, $\alpha$-diversity increased 0.38 species given a four species increase in $\gamma$-diversity.

Multiple-site dissimilarity calculations provided insight into the underlying $\beta$-diversity patterns for ecoregions and latitudinal zones. Turnover of species was identified as the underlying $\beta$-diversity process in five ecoregions (Figure 4a; Table S3): Arctic Coastal Tundra $(t(14)=2.39, p=0.031)$, Arctic Foothills Tundra $(t(9)=3.85, p=0.004)$, Brooks-British Range Tundra $(t(6)=5.499$, 


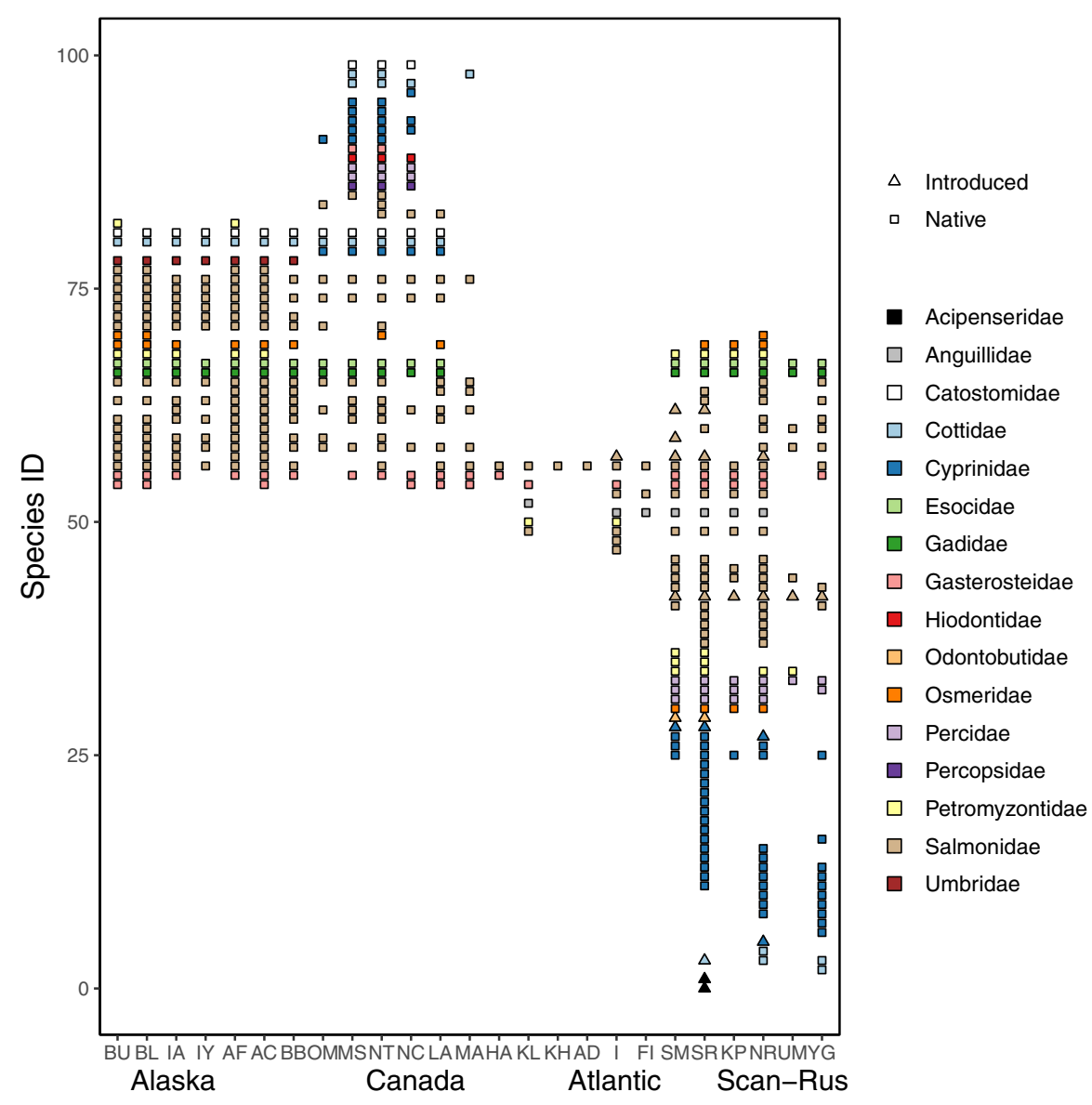

FIGURE 2 Longitudinal distribution pattern of fish species from Alaska to western Russia. Species occurrences for each ecoregion ( $x$-axis) were determined using reference texts (Mecklenburg et al., 2002; Muus \& Dahlström, 1993; Ponomarev, 2017; Scott \& Crossman, 1973) and expert knowledge. Each value on the $y$-axis represents a single species, coloured by taxonomic family. Species identification numbers are referenced in Table S2. Introduced species are represented by triangles. Ecoregions are arranged longitudinally; ecoregions in Alaska, U.S.A.: BU, Beringia Upland Tundra; BL, Beringia Lowland Tundra; IY, Interior Yukon-Alaska Alpine Tundra; IA, Interior Alaska-Yukon Lowland Tundra; AF, Arctic Foothills Tundra; AC, Arctic Coastal Tundra; and BB, Brooks-British Range Tundra. In Canada: NT, Northwest Territories Taiga; OM, Ogilvie-Mackenzie Alpine Tundra; LA, Low Arctic Tundra; MS, Muskwa-Slave Lake Forests; MA, Middle Arctic Tundra; HA, High Arctic Tundra; and NC, Northern Canadian Shield Taiga. In the Atlantic: KH, Kalaallit Nunaat High Arctic Tundra and KL, Kalaallit Nunaat Low Arctic Tundra; I, Iceland Birch Forests and Alpine Tundra; FI, Faroe Islands Boreal Grasslands. In Svalbard and other northern islands: AD, Arctic Desert. In Fennoscandia and Russia; SM, Scandinavian Montane Birch Forest; SR, Scandinavian and Russian Taiga; KP, Kola Peninsula Tundra; RT, Northwest Russian-Novaya Zemlya Tundra; UM, Ural Montane Forests and Tundra; and YG, Yamal-Gydan Tundra

$p=0.002)$, Scandinavian and Russian Taiga $(t(54)=5.63, p<0.001)$, and Scandinavian Montane Birch Forest and Grasslands $(t(31)=2.7$, $p=0.010)$. The nestedness component of $\beta$-diversity was prevalent only in the Iceland Boreal Birch Forests and Alpine Tundra ecoregion $(t(24)=-2.79, p=0.010)$. In two ecoregions, the Arctic Desert $(n=2)$ and the High Arctic Tundra $(n=4), \beta$-diversity was determined to be zero (Figure 4a). In 16 ecoregions, we could not determine differences between the $\beta$-diversity component dissimilarities ( $\beta_{\mathrm{SIM}} \approx \beta_{\mathrm{NES}}$; Figure 4a; Table S3), and in three ecoregions there were insufficient data to determine the components of $\beta$-diversity. Turnover and nestedness component values were not different from one another in either the subarctic $(t(70)=-0.67, p=0.50)$ or high Arctic zones $(t(16)=1.82, p=0.09)$, although there was relatively high dispersion and skew in the $\beta_{\text {SIM }}$ estimate for the high Arctic zone (Figure $4 \mathrm{~b}$ ). Turnover was the dominant $\beta$-diversity component when compared to nestedness in the boreal $(t(51)=5.97, p<0.001)$ and low Arctic zones $(t(57)=5.02, p<0.001$; Figure $3 b)$.

Weak spatial patterns of $\beta$-diversity were evident in three of 25 ecoregions (Table 2): Iceland Boreal Birch Forests and Alpine Tundra, Interior Alaska-Yukon Lowland Taiga, and Scandinavian and Russian Taiga. In the Iceland Boreal Birch Forests and Alpine Tundra, the nestedness component of $\beta$-diversity contributed to differences across space, given that values of $\beta_{\text {nes }}$ were positively correlated with geographic distance. Conversely, the turnover component of $\beta$-diversity, $\beta_{\text {sim }}$, was positively correlated with geographic distance between pairs of hydrobasins in the Interior Alaska-Yukon Lowland Taiga and the Scandinavian and Russian Taiga. Beta-diversity and its component parts of nestedness and turnover were not correlated with geographic distance in 12 of the 25 ecoregions, and in the remaining 10 ecoregions, correlations could not be determined due 
FIGURE 3 Response of hydrobasin $\alpha$ diversity to latitude (a) and $\gamma$-diversity (b). Each point on the plots represents a single hydrobasin. The log-linear relationship between $\alpha$-diversity and latitude $( \pm 1 S E)$ is shown for latitudes below $70.7^{\circ} \mathrm{N}$ (a)

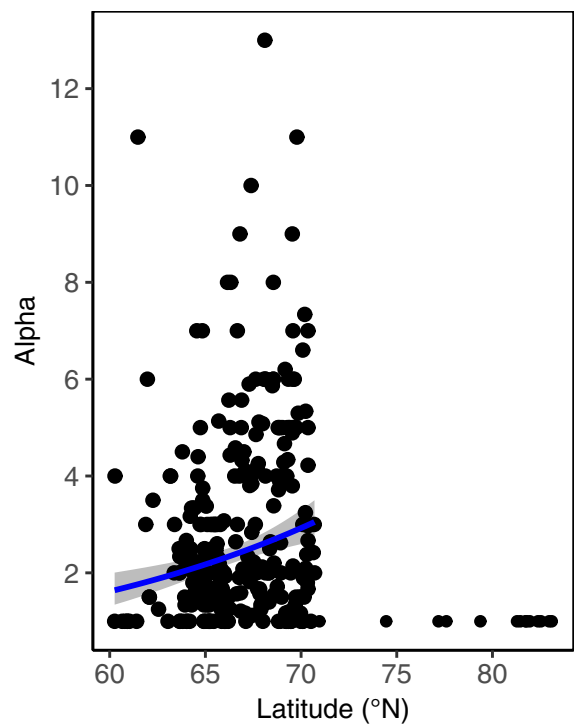

(b)

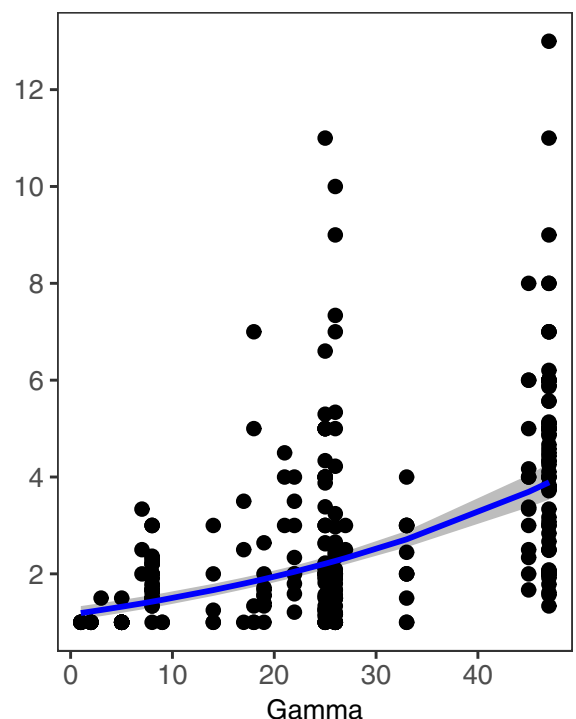

to limited data or lack of variance in richness between hydrobasins (Table 2).

Spatial patterns of $\beta$-diversity varied by latitudinal zone (Table 2 ). In the boreal and subarctic, where the maximum distance between hydrobasins was greatest, total $\beta$-diversity was weakly positively correlated with distance between hydrobasins. In these two zones, the dissimilarity between hydrobasin species assemblages across the spatial extent of the study arose primarily from the turnover component of $\beta$-diversity, which was also positively correlated with spatial distance. The nestedness component of $\beta$-diversity was not significantly correlated with spatial distance, though correlation coefficients were similar in magnitude to those found for total diversity. In the low Arctic and high Arctic, no correlation was found between hydrobasin assemblage dissimilarity and spatial distance for total $\beta$-diversity, the turnover component of $\beta$-diversity, or the nestedness component of $\beta$-diversity.

\section{2 | Regional diversity comparisons}

Rarefied ( $n$ samples $=921$ ) fish species richness, as an estimate of $\gamma$-diversity at the ecoregion scale, was highest, with a richness of nearly 20 species in the Scandinavian and Russian Taiga and Arctic Coastal Tundra (Table 3; Figure 5a). Fish species richness in the Scandinavian Montane Birch Forest and Grasslands and BrooksBritish Range Tundra were 18\% and 54\% lower, respectively, than their neighbouring, lower elevation ecoregions. The rarefied richness in the Iceland Boreal Birch Forests and Alpine Tundra was lower than in all of the other ecoregions on mainland continents, with a richness of three species.

Comparisons between the Arctic Coastal Tundra and the BrooksBritish Range Tundra in Alaska, and between the Scandinavian and Russian Taiga and the Scandinavian Montane Birch Forest and Grasslands using the ecological null hypothesis put forward by
Cayuela et al. (2015)-that two or more samples were drawn randomly from the same species pool-was tested using rarefaction curves. Rarefaction curves between the Arctic Coastal Tundra and the Brooks-British Range Tundra differed $\left(n_{\text {iter }}=750, Z_{\text {obs }}=9,419\right.$, $p=0.001$ ), suggesting that there were differences in either species composition or richness. Rarefaction curves from the Scandinavian and Russian Taiga and the Scandinavian Montane Birch Forest and Grasslands were similar ( $n_{\text {iter }}=750, Z_{\text {obs }}=3,447, p=0.569$ ), suggesting differences in species richness or composition between stations in the two ecoregions were no greater than what would be anticipated from random sampling of the same species pool.

When comparing rarefaction curves across distant ecoregions, we failed to reject the biogeographical null hypothesis put forward by Cayuela et al. (2015) - that two or more samples were drawn from assemblages that share species richness profiles-in one of seven pairs. There was no significant difference between the rarefaction curves in the Scandinavian and Russian Taiga and the Arctic Coastal Tundra $\left(n_{\text {iter }}=200, Z_{\text {obs }}=254, p=0.560\right)$. The rarefaction curves for the Iceland Boreal Birch Forests and Alpine Tundra, which had the smallest species pool and only three represented species, differed from those for other ecoregions (i.e. higher values of $Z_{\text {obs }}$ ). The curves for the Iceland Boreal Birch Forests and Alpine Tundra and for the Scandinavian Montane Birch Forests and Grasslands could not be assessed given the low species richness in both of those ecoregions.

Mean $\alpha$-diversity was highest in the Scandinavian and Russian Taiga at approximately eight species, with similar mean $\alpha$-diversity in the Arctic Coastal Tundra, and Brooks-British Range Tundra (Table 3; Figure 6a). Mean $\alpha$-diversity in the Scandinavian Montane Birch Forest and Grasslands was reduced by two species compared to the adjacent Scandinavian and Russian Taiga ecoregion (Figure $5 b$ ). Overall, $\alpha$-diversity was reduced in the high-elevation ecoregions (Brooks-British Range Tundra and Scandinavian Montane Birch Forest and Grasslands) when compared to that of adjacent 
TABLE 1 Diversity values for all ecoregions where fish data were available

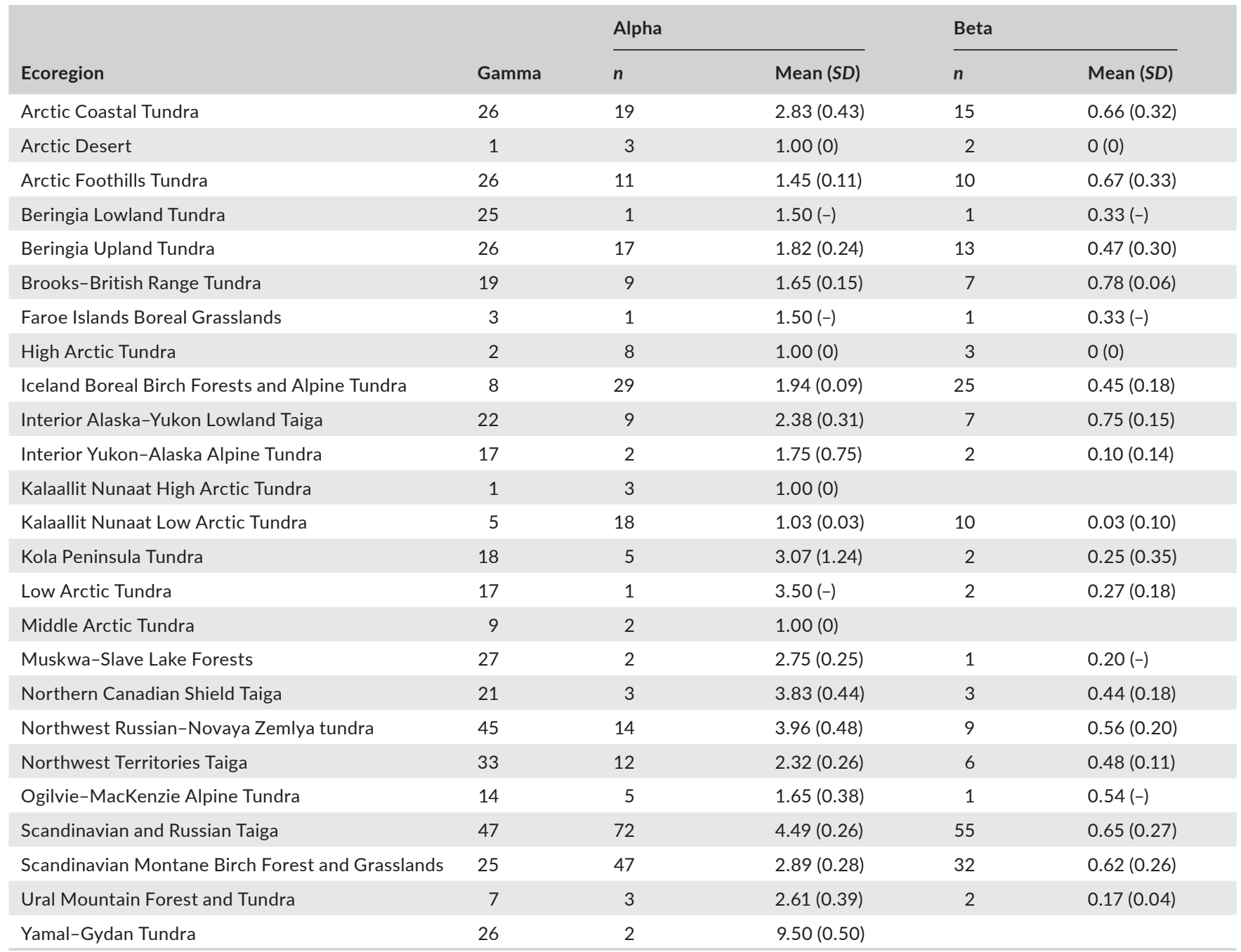

Note: Gamma-diversity was based on literature (Mecklenburg et al., 2002; Muus \& Dahlström, 1993; Ponomarev, 2017; Scott \& Crossman, 1973) and expert knowledge. Alpha-diversity was determined as the average species richness of all sample stations within a hydrobasin, and $\beta$-diversity was determined from Sørensen dissimilarities of sample stations within a hydrobasin. The number, $n$, and mean (SD) are provided for each ecoregion.

low-elevation ecoregions (Figure 5b). Among the five ecoregions, mean hydrobasin $\alpha$-diversity was lowest in the Iceland Boreal Birch Forests and Alpine Tundra, with only three species.

Using multiple-site dissimilarity calculations we found that $\beta$-diversity was greatest in the Arctic Coastal Tundra, the Brooks-British Range Tundra, and the Fennoscandian area of the Scandinavian and Russian Taiga (Table 3). Beta-diversity was lower in the Scandinavian Montane Birch Forest and Grasslands and lowest in the Iceland Boreal Birch Forests and Alpine Tundra (Figure 6b). Average $\beta_{\text {SOR }}$ differed significantly between all ecoregions (ANOVA $F(4,5,995)=303, p<0.001$, all pairwise tests $p<$ 0.003; Table 3). Comparisons of the turnover and nestedness components revealed higher values of $\beta_{\mathrm{SIM}}$ compared to $\beta_{\mathrm{NES}}$ in the Arctic Coastal Tundra $(t(799)=35.37, p<0.001)$, Brooks-British Range Tundra ( $t(399)=18.39, p<0.001)$, Scandinavian and Russian Taiga $(t(2,799)=37.27, p<0.001)$, and the Scandinavian Montane Birch Forest and Grasslands $(t(1,499)=24.41, p<0.001$; Figure $5 c)$.
Beta-diversity in the Iceland Boreal Birch Forests and Alpine Tundra exhibited the opposite pattern, where dissimilarity from nestedness was greater than the dissimilarity from turnover $(t(499)=-20.59, p<$ 0.001 , Figure 6b).

\section{DISCUSSION}

By examining the spatial patterns of $\gamma^{-}, \alpha$-, and $\beta$-diversity, we provide the first baseline for understanding processes that govern fish community assembly and species richness in the circumpolar Arctic. Because community richness and composition depend upon the dispersal abilities of the fishes, historic and contemporary barriers to colonisation, and environmental characteristics that influence occupancy (Griffiths, 2015; Oswood, Reynolds, Irons, \& Milner, 2000; Tonn, Magnuson, Rask, \& Toivonen, 1990), broad-scale patterns of 
(a)

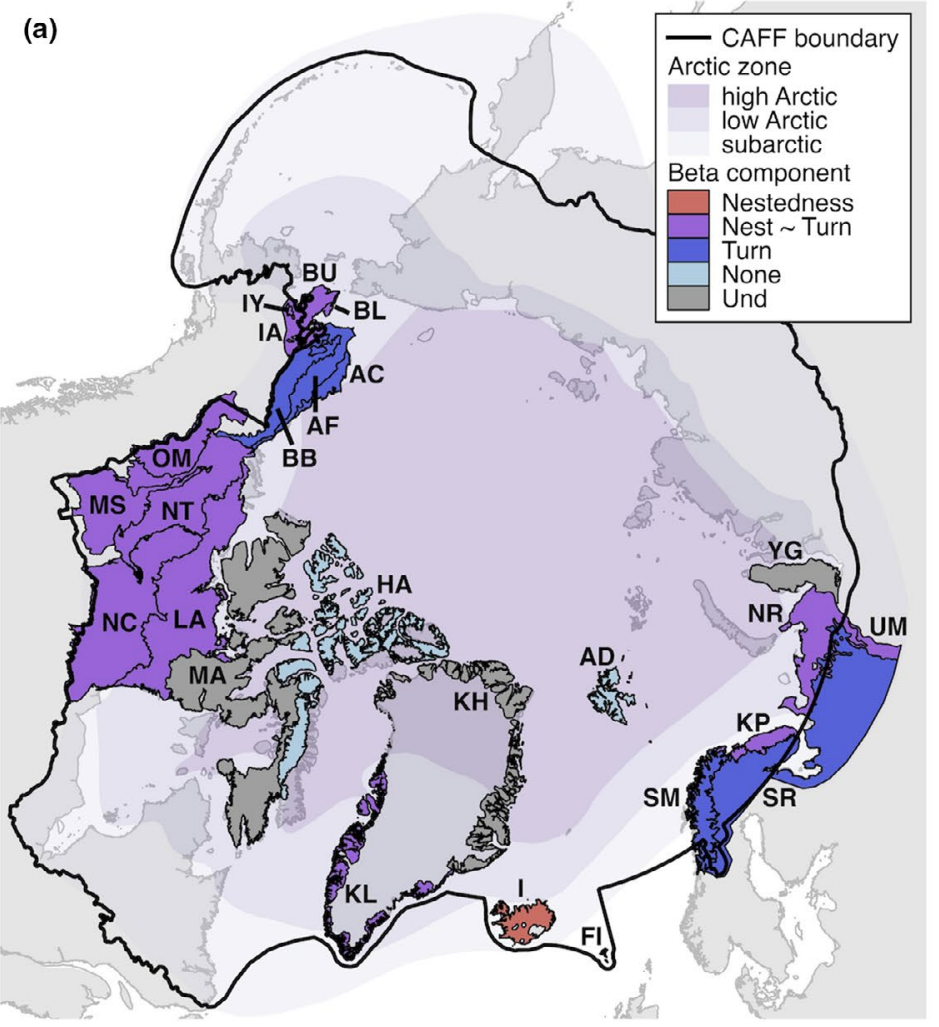

(b)

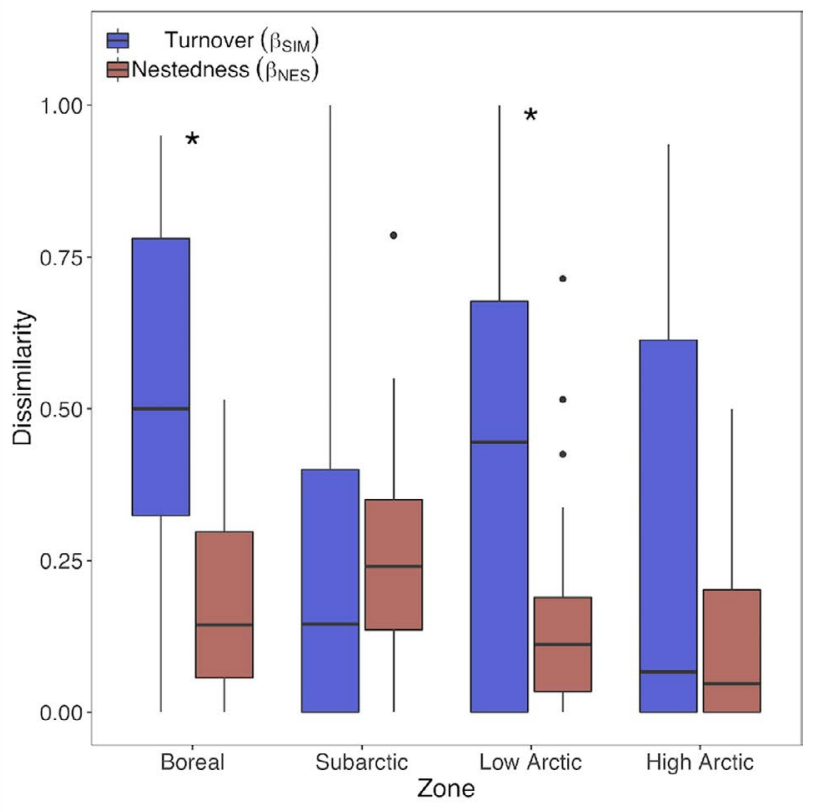

FIGURE 4 Dominant components of $\beta$-diversity in ecoregions (a) of the circumpolar Arctic characterised as nestedness, turnover, no diversity (none, $\beta=0$ ), similar nestedness and turnover (nest turn), or undetermined due to small sample size (Und). Box and whisker plots of turnover $\left(\beta_{\mathrm{SIM}}\right)$ and nestedness $\left(\beta_{\mathrm{NES}}\right)$ components of $\beta$-diversity for each latitudinal zone (b). Statistical differences in turnover and nestedness are indicated with an * above the zone. Boxes span the first to third quartile, the line within the box is the median, and points beyond the whiskers are outliers. Ecoregions are BU, Beringia Upland Tundra; BL, Beringia Lowland Tundra; IY, Interior Yukon-Alaska Alpine Tundra; IA, Interior Alaska-Yukon Lowland Tundra; AF, Arctic Foothills Tundra; AC, Arctic Coastal Tundra; BB, Brooks-British Range Tundra; NT, Northwest Territories Taiga; OM, Ogilvie-Mackenzie Alpine Tundra; LA, Low Arctic Tundra; MS, Muskwa-Slave Lake Forests; MA, Middle Arctic Tundra; HA, High Arctic Tundra; NC, Northern Canadian Shield Taiga; KH, Kalaallit Nunaat High Arctic Tundra; KL, Kalaallit Nunaat Low Arctic Tundra; I, Iceland Birch Forests and Alpine Tundra; FI, Faroe Islands Boreal Grasslands; AD, Arctic Desert; SM, Scandinavian Montane Birch Forest; SR, Scandinavian and Russian Taiga; KP, Kola Peninsula Tundra; RT, Northwest Russian-Novaya Zemlya Tundra; UM, Ural Montane Forests and Tundra; and YG, Yamal-Gydan Tundra. The black line indicates the Conservation of Arctic Flora and Fauna (CAFF) boundary of the Arctic

fish species $\alpha$-, $\beta$-, and $\gamma$-diversity varied with latitude, isolation, and coarse ecoregion characteristics (e.g. elevation or area). Our evaluation of these biodiversity patterns provides information on community regulation (i.e. factors that control richness, abundance, or composition) that can improve monitoring and assessments of biodiversity change or persistence in the future (Gotelli et al., 2017).

Gamma-diversity was lowest in the highest latitude ecoregions (i.e. Middle Arctic Tundra and High Arctic Tundra in Canada, Kalaallit Nunaat High Arctic Tundra in Greenland, and Arctic Desert in Svalbard), because limited connections to glacial refugia, time since glaciation events, harsh environmental conditions, and species dispersal abilities limit species richness with increasing latitude (Griffiths, 2015; Schleuter et al., 2012). Recent warming of marine and freshwaters in the Arctic may facilitate the range expansion of species, which could lead to compositional change (Hayden et al., 2017; Reist et al., 2006). In fact, climate change now facilitates the northward movement of many fishes previously restricted by low temperatures in high Arctic environments. Diadromous or euryhaline fish species, which are fairly common in northern areas, may ascend non-natal watercourses to colonise new freshwater localities in the high Arctic. For example, threespine stickleback Gasterosteus aculeatus recently appeared in surveys of freshwaters at Zackenberg, Greenland in Kalaallit Nunaat High Arctic Tundra (Nielsen, Hamerlik, \& Christoffersen, 2012), and on Svalbard in the remote Arctic Desert (Svenning, Aas, \& Borgstrøm, 2015).

Many of the fish species in high latitudes of Canada and Europe are found in both historically unglaciated and glaciated regions, suggesting northward (in Europe, north and west) movement of fishes from a colonising source (i.e. refugia) after glacial retreat (Griffiths, 2015; Koljonen et al., 1999). In contrast, the Beringia refugia provided protection for freshwater fishes during the most recent Pleistocene glaciation event (Christiansen et al., 2013; Oswood et al., 2000), which has resulted in increased species richness at high latitudes (about $70.3^{\circ} \mathrm{N}$ ) of Alaska (Oswood et al., 2000), where $\gamma$ diversity was as high as 26 fish species. Eighty-one per cent of the fishes found in northern Alaska (i.e. Arctic Coastal Tundra and the 


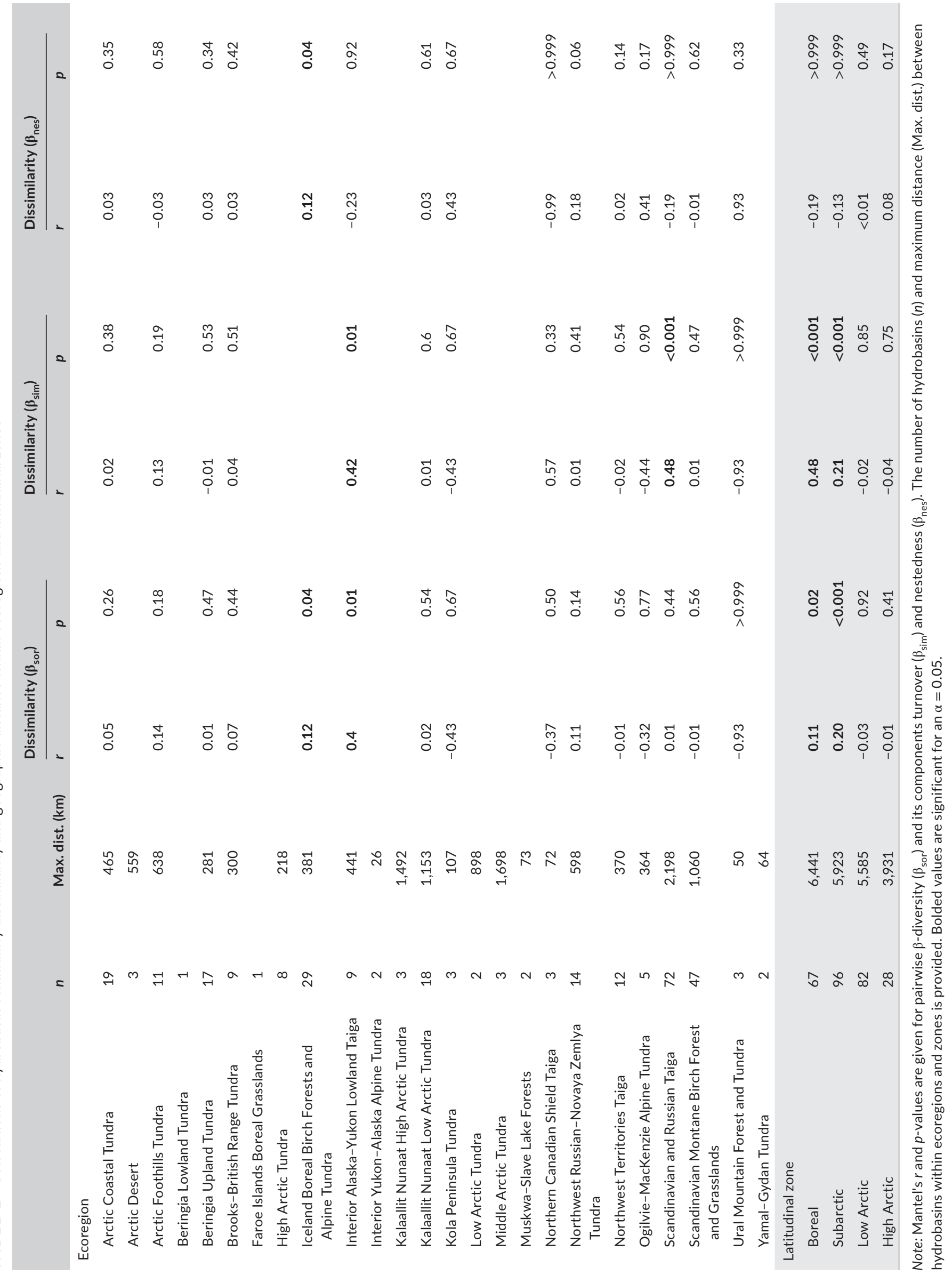


Arctic Foothills Tundra) persisted in the Beringian refugia (Oswood et al., 2000). Northernmost Scandinavia, which was re-colonised from an eastern refuge, showed higher fish species diversity than Scandinavian Mountain Birch Forests regions (Hewitt, 2000; Nesbø, Fossheim, Vøllestad, \& Jakobsen, 1999; Østbye, Bernatchez, Næsje, Himberg, \& Hindar, 2005). These studies support our finding that the Scandinavian Montane Birch Forests and Grasslands ecoregion had reduced $\alpha$-diversity compared to the adjacent low-elevation ecoregion, indicating the importance of barriers to colonisation at higher altitudes. It should also be noted that current ecoregion definitions are not always ideal for the study of fish diversity and distributions, which have been influenced by historical conditions including a complex suite of glacial melting channels, ice-dammed lakes, terrestrial uplift or rebound, and watercourse alterations (e.g. Mangerud et al., 2004). Constructing additional geographic regions, such as palaeodrainage basins (see Dias et al., 2014), may benefit biodiversity analyses of fish communities that have formed over thousands of years since deglaciation.

Due to the refuge provided during the last glacial advance, fish species richness does not decline northward in hydrobasins of the Arctic Coastal Tundra. Instead, species richness increases slightly from the south to north, which corresponds with the additional presence of anadromous fishes at the Beaufort Sea coast (Craig, 1984; Laske et al., 2016). Among all stations, $\alpha$-diversity was relatively consistent from $60^{\circ}$ to $70^{\circ} \mathrm{N}$, a pattern that may result from the overwhelming proportion of sites in Alaska's high Arctic and the region's biogeography and glacial history. Because of the sampling imbalance across countries and a lack of stations in vast areas of the subarctic (e.g. Canada and Russia), we cannot clearly determine whether the pattern of increasing $\alpha$-diversity with latitude occurs uniformly across the circumpolar Arctic.

In Arctic Canada, freshwaters extend to roughly $83^{\circ} \mathrm{N}$ and species richness declines with latitude are evident, but declines are also strongly associated with lack of connectivity among freshwater habitats in the Canadian Archipelago (Christiansen et al., 2013). The abrupt loss in $\alpha$-diversity at latitudes above $71^{\circ} \mathrm{N}$ probably relates directly to the lack of contiguous landmass, which includes only parts of Siberia, Greenland, the Canadian Archipelago, and northern Arctic islands (e.g. Svalbard). The lack of freshwater connectivity to Greenland, the Canadian Archipelago, and northern Arctic islands limits colonisation to only anadromous species (Christiansen et al., 2013). However, limited data, particularly on continental Eurasia, may be preventing a clear interpretation of our results. At least seven to 10 species of freshwater/anadromous fish occur in the high Arctic from the Ural Mountains east to the Indigirka River in Siberia (Novikov et al., 2000; Romanov, Zuykova, \& Bochkarev, 2016), but their latitudinal distribution patterns are unclear.

Location and isolation affected both $\gamma$ - and $\alpha$-diversity; in high Arctic ecoregions and on islands, $\alpha$-diversity was constrained by the available species pool. The size of the regional species pool $(\gamma$ diversity) is tightly coupled to lower scale processes, including the dispersal and persistence of species within a region (Hillebrand et al., 2018; Rolls et al., 2018). At larger scales, historic and contemporary conditions limit species access to ecoregions. The Scandinavian Montane Birch Forest and Grasslands is at higher elevation and deglaciated later than Scandinavian and Russian Taiga (e.g. Mangerud et al., 2004), corresponding with lower $\gamma$ - and $\alpha$-diversity today. Similarly, the Brooks-British Range Tundra was glaciated during the last Pleistocene event, and combined with current elevation effects (e.g. stream gradients) the fish fauna of this ecoregion is dissimilar compared with the other ecoregions in Alaska (Hershey et al., 2006; Oswood et al., 2000). We found, by comparing rarefaction curves, that the Brooks-British Range Tundra differed either in species richness or composition from the Arctic Coastal Tundra. By examining the identities of fish found in these two ecoregions, differences arose from loss of species across ecoregion boundaries (Mecklenburg et al., 2002). In Iceland, an isolated region with low $\alpha$ - and $\gamma$-diversity, freshwater fish dispersal to the island is limited by great distance $(>1,000 \mathrm{~km})$ to mainland freshwaters. As a result, only diadromous or euryhaline species have colonised (Christiansen et al., 2013), limiting species diversity.

While Salmonidae (48-52 species) is a diverse, cold-water adapted, and wide-ranging family of fishes (Erkinaro et al., 2019; Siwertsson et al., 2010; Woods et al., 2012), other taxonomic groups (e.g. Anguillidae, Cobitidae, and Umbridae) have more limited diversity and geographic distributions in the Arctic (Christiansen et al., 2013). Across the study area, $14 \%$ of fishes (excluding introduced species) spanned both Nearctic and Palearctic continents (including Arctic charr, burbot Lota lota, pike Esox lucius, threespine stickleback, ninespine stickleback Pungitius pungitius, and Arctic cisco Coregonus autumnalis). The remaining species turned over or were replaced. The assessment of $\beta$-diversity compared diversity at two different scales (the ecoregion- $\gamma$-diversity; and the hydrobasin- $\alpha$-diversity), with dissimilarities arising from species replacement (i.e. turnover) or loss (i.e. nestedness; Anderson et al., 2011; Baselga, 2010). We found that in a majority of ecoregions, both replacement and loss of species from hydrobasin to hydrobasin contributed to $\beta$-diversity. In ecoregions with robust sampling, however, turnover was the dominant process, suggesting that a change in species composition between basins was more prevalent than losses of species from a primary, species rich location. Turnover may result from directional change in species composition that occur along a predefined spatial or environmental gradient (e.g. temperature; elevation), or from a non-directional change that occurs among sites within a given area (e.g. lake depth; Anderson et al., 2011; Legendre, Borcard, \& PeresNeto, 2005)

The virtual lack of $\beta$-diversity in northern ecoregions (i.e. Arctic Desert, High Arctic Tundra, Kalaallit Nunaat Low Arctic Tundra) was not surprising given the low richness of regional species pools (Mecklenburg et al., 2002; Muus \& Dahlström, 1993; Scott \& Crossman, 1973). The high Arctic zone did not display a strong pattern of species turnover or nestedness, probably because patchy data obscured true $\beta$-diversity patterns. Most species in the high Arctic were found in one ecoregion (Arctic Coastal Tundra, 21 spp.), and only one shared species (Arctic charr) was represented in the remaining four ecoregions (High Arctic Tundra, Middle Arctic 
TABLE 3 Gamma-diversity $\left(S_{\text {rare }}\right), \alpha$-diversity $\left(\alpha_{\text {rare }}\right)$, multiple-site $\beta$-diversity $\left(\beta_{\text {SOR }}\right)$, and its components turnover $\left(\beta_{\text {SIM }}\right)$ and nestedness $\left(\beta_{\text {NES }}\right)$ for a subset of five ecoregions with robust fish species presence-absence data

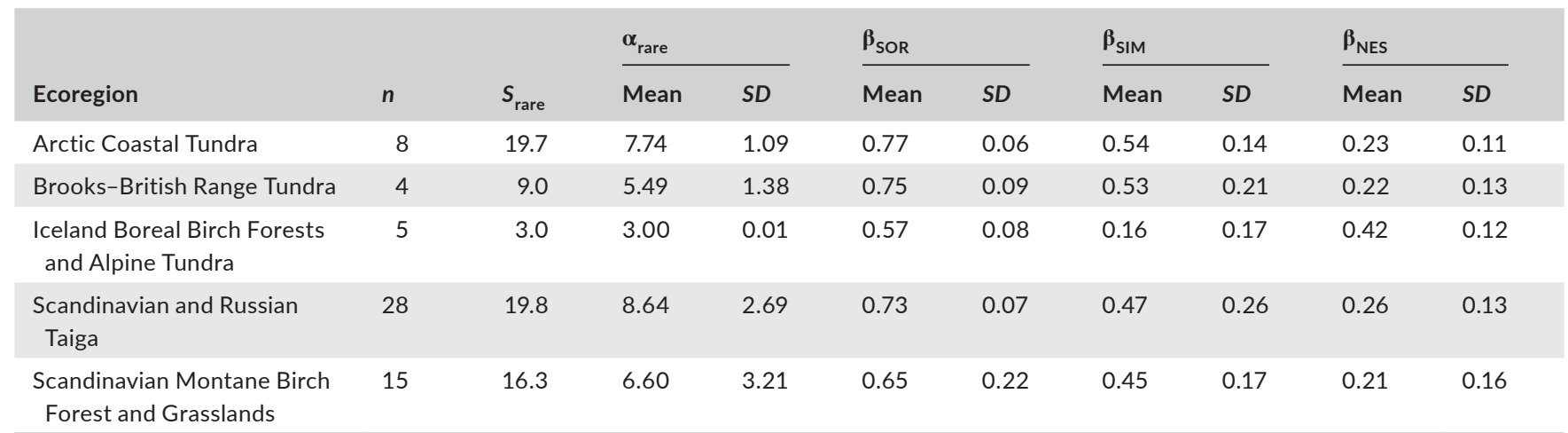

Note: The number of basins $(n)$ used to determine the mean and standard deviation of $\alpha_{\text {rare }}$ and $\beta$-diversity estimates based on resampling. Sample size for $\beta$-diversity resampling is 100 .

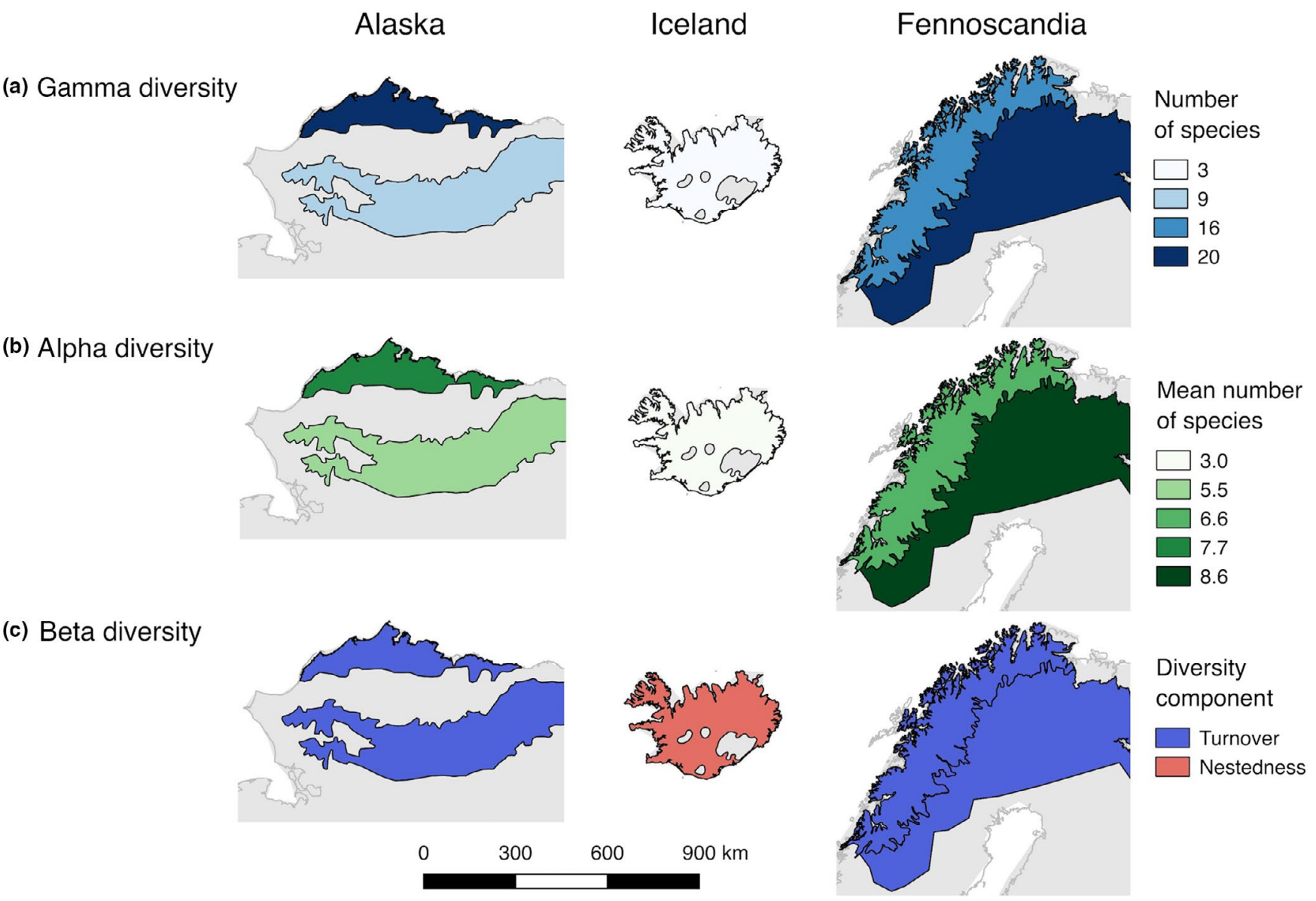

FIGURE 5 Gamma-diversity (a), $\alpha$-diversity (b), and the primary $\beta$-diversity (c) components for the Alaska Coastal Tundra and BrooksBritish Range Tundra in Alaska, the Iceland Boreal Birch Forests and Alpine Tundra, and the Scandinavian Montane Birch Forest and Grasslands and Scandinavian and Russian Taiga in Fennoscandia

Tundra, Kalaallit Nunaat High Arctic Tundra, and the Arctic Desert). However, low $\gamma$-diversity and consistent fish assemblages, often including Holarctic species (e.g. Arctic charr or threespine stickleback), would limit the amount of possible variation in communities of the high Arctic. Potentially, with increased spatial sampling, patterns of $\beta$-diversity in the high Arctic may become apparent. Those sites that are particularly harsh (i.e. isolated, and at high latitudes) may be occupied only by a subset of the richest assemblage, including only species that are either physiologically tolerant or migratory (Griffiths, 2010; Henriques-Silva, Lindo, \& Peres-Neto, 2013).

We anticipated that the dissimilarity between hydrobasin assemblages would increase with geographic distance (Beisner et al., 2006; Soininen et al., 2007). In other words, distant assemblages would share fewer species than proximate assemblages-either as 
FIGURE 6 Box and whisker plots of ecoregion $\alpha$-diversity (a) and fish assemblage dissimilarity due to the turnover $\left(\beta_{\mathrm{SIM}}\right)$ and nestedness $\left(\beta_{\mathrm{NES}}\right)$ components of $\beta$-diversity (b). Differences in $\alpha$-diversity are indicated by the letters above each box, shared letters indicate no statistical difference of means. Statistical differences in mean turnover and nestedness are indicated with an * above the ecoregion. Boxes span the first to third quartile, the line within the box is the median, and points beyond the whiskers are outliers (a)

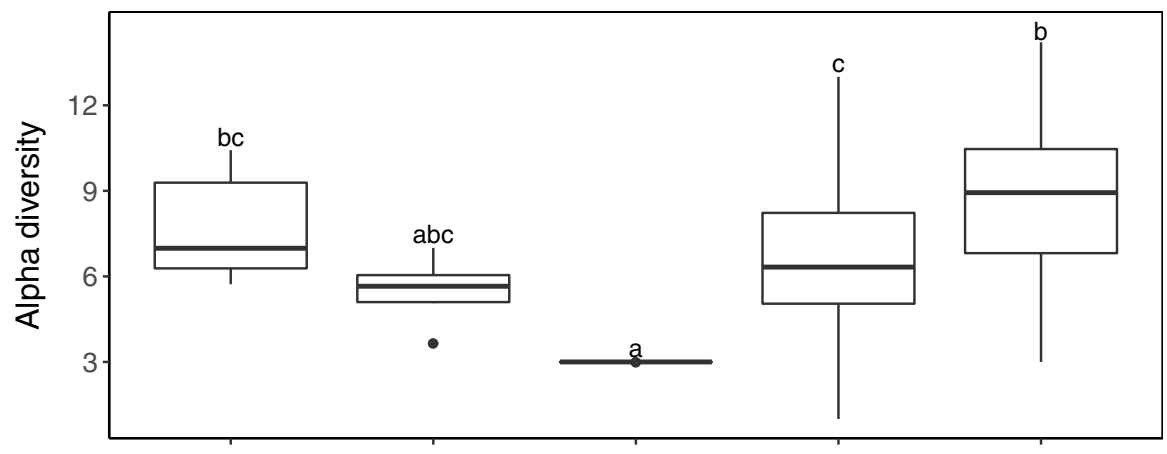

(b)

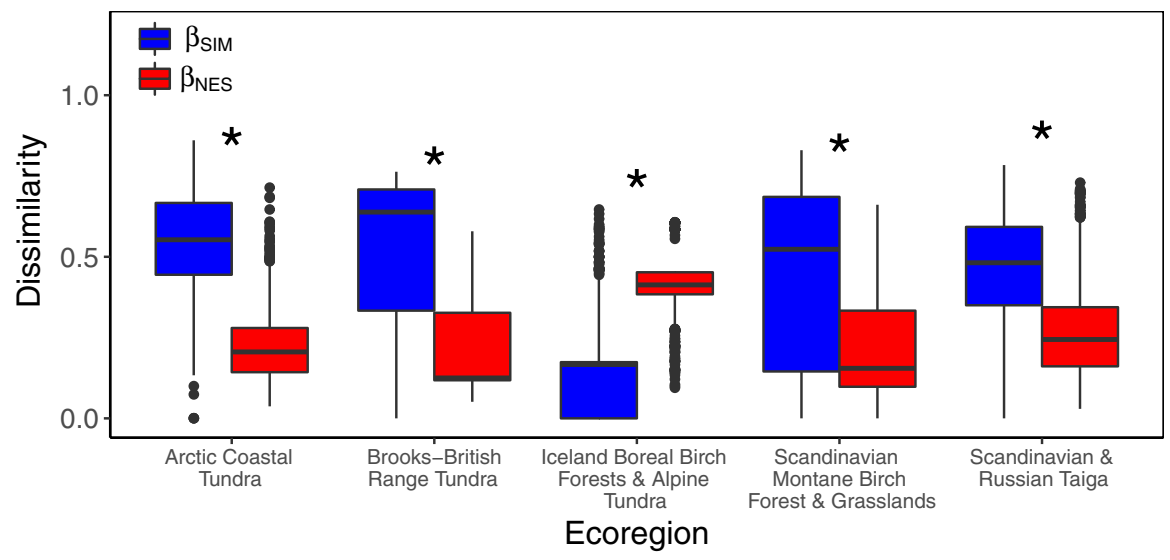

a result of species replacement (i.e. turnover) or loss (i.e. nestedness). Species turnover was correlated with geographic distance at lower latitudes, in the boreal and subarctic zones, so dissimilarity between distant hydrobasin assemblages arose from replacement of fish species rather than from changes in fish species richness. On a circumpolar scale, patchy distributions of species with more southerly distributions may contribute to turnover, since some families or species are restricted to either the Nearctic (e.g. Catostomidae and Hiodontidae) or the Palearctic (e.g. Balitoridae and Cobitidae; Christiansen et al., 2013). The Cyprinidae family occurs in both the Nearctic and Palearctic, making up $38 \%$ of the species in the Nearctic and $62 \%$ of the species in the Palearctic (Christiansen et al., 2013; Muus \& Dahlström, 1993; Scott \& Crossman, 1973), yet none of the Cyprinidae species occur on both continents.

In the Scandinavian and Russian Taiga, there was little difference in mean $\alpha$-diversity across the sampled hydrobasins, but distant sites were dissimilar due to species replacement; hydrobasin assemblages in Sweden and southern Finland differed from those in western Russia. Rapid changes in the identities of species along a spatial gradient may identify ecotones, or the transitional boundary between two biological assemblages (Guerin, Biffin, \& Lowe, 2013; Leprieur et al., 2011). This particular terrestrial ecoregion covered a large spatial extent that overlapped two major drainages (Northern Baltic Sea and the Barents Sea), considered as two flow-based Freshwater Ecoregions (Abell et al., 2008). The spatial breadth of the ecoregion had a major impact on our assessment of $\gamma$-diversity from literature and from data collected for this study, by adding species either along a longitudinal gradient or with increasing area. Gammadiversity, based on rarefaction curves, in the Arctic Coastal Tundra and Fennoscandian portion of the Scandinavian and Russian Taiga were similar. Those estimates included $77 \%$ (20 of 26 species) of the known species in the Arctic Coastal Tundra and only 43\% (20 of 47 species) of the known species in the Scandinavian and Russian Taiga, which may indicate that the freshwaters to the east (in Russia) contain additional species. Each of the other terrestrial ecoregions (Olson et al., 2001) subdivided the Freshwater Ecoregions (Abell et al., 2008), and accounted for additional landscape features such as isolation (e.g. Svalbard) or mountain ranges (e.g. the Brooks Range in Alaska). Community variation was often not associated with geographic distance (83\% of ecoregions), however, so other factors such as historical conditions during deglaciation, species co-occurrence, non-spatial gradients, or environmental heterogeneity may underlie the processes of turnover or nestedness (Anderson et al., 2011; Baselga, 2013).

At regional scales, environmental heterogeneity across hydrobasins can affect factors that control fish species richness, composition, and community assembly (Gotelli et al., 2017; Magnuson et al., 1998). In our study, patterns of diversity did not always differ in distant ecoregions (e.g. Arctic Coastal Tundra and Scandinavian and Russian Taiga), suggesting that mechanisms of community regulation may operate similarly on dissimilar regional species pools (Kraft et al., 2011; Tonn et al., 1990). In the Arctic Coastal Tundra 
of Alaska, coastal hydrobasins with large river deltas contained a far greater diversity of species (Christiansen et al., 2013; Craig, 1984; Wrona et al., 2006), including regionally rare species (e.g. sockeye salmon Oncorhynchus nerka), anadromous species (e.g. Dolly Varden Salvelinus malma), and freshwater species (e.g. longnose sucker Catostomus catostomus). Because turnover was the predominant process in the Arctic Coastal Tundra ecoregion, other hydrobasins did not represent disaggregated subsets of the richest location. Instead, species replaced one another along environmental gradients (e.g. distance from major river, isolation) given their individual dispersal abilities (Craig, 1984; Laske et al., 2016; Oswood et al., 2000).

Isolation may have profound effects on the distribution of fishes across landscapes, and on our understanding of environmental gradients that effect biodiversity (Brittain et al., 2009; Magnuson et al., 1998; Schleuter et al., 2012). Freshwater habitats on islands (e.g. the Canadian Archipelago, Svalbard, Iceland) are considerably more isolated than freshwater habitats on contiguous land masses (e.g. Eurasian Arctic), and had only a subset of species found elsewhere. In mountainous regions, physical barriers limit species access from adjacent lower elevation ecoregions and promote the creation of discrete fish communities (Degerman \& Sers, 1992; Hershey et al., 1999). Lakes of the Brooks-British Range Tundra are occupied by specific communities that turnover along specific geomorphic constraints (Hershey et al., 1999), including channel gradients, altitude, and lake area or depth (Degerman \& Sers, 1992; Hershey et al., 2006; Holmgren \& Appelberg, 2000). In addition, in many species-poor regions, historical conditions during deglaciation and ecological opportunity have facilitated fish divergence via resource polymorphism and ecological speciation events (Hershey et al., 2006; Siwertsson et al., 2010; Woods et al., 2012) that can have very important trophic consequences within communities (Lucek, Kristjánsson, Skúlason, \& Seehausen, 2016; Thomas et al., 2017; Woods et al., 2012).

Across the circumpolar Arctic, fish biodiversity depended upon the historic and modern characteristics of the ecoregion or latitudinal zone where they occurred. However, some of the variability we found among hydrobasins was probably due to differences in sample availability rather than the environment, given that streams and lakes were not sampled in relation to their abundance or with consistency across ecoregions. Additionally, in hydrobasins with fewer sampled stations, we probably missed a greater number of species because of non-detection. Potentially, reduced $\alpha$-diversity in hydrobasins with fewer sample stations may be overly influential in our circumpolar analyses where all hydrobasins were considered, reducing average $\alpha$-diversity and increasing the contribution of nestedness to $\beta$-diversity patterns. The effect of area on species diversity at larger spatial scales (i.e. that of the ecoregion) was also difficult to ascertain because of disparities in the distribution and number of hydrobasins with station data.

This study takes the first steps in determining large-scale patterns of freshwater fish biodiversity throughout the circumpolar Arctic using a unique data compilation. It is important to evaluate the current biodiversity patterns and to provide a baseline to improve our ability to detect temporal species turnover and spatial dissimilarity (Hillebrand et al., 2018; Socolar et al., 2016). Changes in climate, land use, and biotic exchange will have profound effects on Arctic fish biodiversity and the structure and function of communities and food webs in the future (Hayden et al., 2017; Sala et al., 2000; Wrona et al., 2006). In this respect, freshwaters in the subarctic zone should be monitored intensively, because these waterbodies are most likely to experience encroachment and expansion of warmwater adapted species from the boreal region (Rolls et al., 2018). In future fish diversity assessments, research should look beyond the species level towards intraspecific diversity, which is known to repeatedly occur in many of the studied circumpolar areas (Skúlason et al., 2019; Taylor, 1999), and is an important contributor to freshwater food web structure and ecosystem function (Power, Reist, \& Dempson, 2008; Thomas et al., 2017; Woods et al., 2012). An underlying question is whether to monitor the richest assemblages or focus on ecosystem gradients or factors that promote and maintain fish diversity. Future studies examining patterns and drivers of Arctic biodiversity should strive to combine extensive old and new data from the circumpolar regions to test for changes in observed patterns and the consequences of both among- and within-species variation on design and implementation of monitoring frameworks used to preserve freshwater biodiversity.

\section{ACKNOWLEDGMENTS}

We thank the staff of the Conservation of Arctic Flora and Fauna office. We also thank three anonymous reviewers for their comments on this manuscript. Thank you to the co-leads of the Freshwater Group for the Circumpolar Biodiversity Monitoring Plan-Joseph Culp and Willem Goedkoop-for their commitment to the process and for comments provided on an early draft of this manuscript. Thank you Brianna Levenstein and Julia Howland for digitizing data. We thank everyone who participated in field work to collect the circumpolar fish data used in this study. Financial support was provided to K.K.K. (Academy of Finland, projects 1140903, 1268566), K.H. and J.Ö. (Swedish Environmental Protection Agency), P.-A.A. (Norwegian Research Council, projects no. 183984, 186320, 213610), K.S.C. (Danish Environmental Agency), and R.R. (Ministry of Science and Higher Education (Russia), project no. AAAA-A17-117112850235-2). Any use of trade, firm, or product names is for descriptive purposes only and does not imply endorsement by the U.S. Government.

\section{ORCID}

Sarah M. Laske iD https://orcid.org/0000-0002-6096-0420 Brian Hayden (iD https://orcid.org/0000-0002-8524-7373 Jani Heino (iD https://orcid.org/0000-0003-1235-6613 Jennifer Lento (iD https://orcid.org/0000-0002-8098-4825 Martin-A. Svenning (D) https://orcid.org/0000-0002-8276-9686

\section{REFERENCES}

Abell, R., Thieme, M. L., Revenga, C., Bryer, M., Kottelat, M., Bogutskaya, N., ... Petry, P. (2008). Freshwater ecoregions of the world: A new 
map of biogeographic units for freshwater biodiversity conservation. BioScience, 58, 403-414. https://doi.org/10.1641/b580507

Anderson, M. J., Crist, T. O., Chase, J. M., Vellend, M., Inouye, B. D., Freestone, A. L., ... Swenson, N. G. (2011). Navigating the multiple meanings of $\beta$ diversity: A roadmap for the practicing ecologist. Ecology Letters, 14, 19-28. https://doi.org/10.1111/j.1461-0248.2010.01552.x

Appelberg, M. (Ed.). (2000). Swedish standard methods for sampling freshwater fish with multi-mesh gillnets: Stratified random sampling with Nordic multi-mesh gillnets provide reliable whole-lake estimates of the relative abundance and biomass of freshwater fish in temperate lakes. Fiskeriverket Information, 1, 3-32.

April, J., Hanner, R. H., Dion-Côté, A.-M., \& Bernatchez, L. (2013). Glacial cycles as an allopatric speciation pump in North-Eastern American freshwater fishes. Molecular Ecology, 22, 409-422. https://doi. org/10.1111/mec.12116

Baselga, A. (2010). Partitioning the turnover and nestedness components of beta diversity. Global Ecology and Biogeography, 19, 134-143. https://doi.org/10.1111/j.1466-8238.2009.00490.x

Baselga, A. (2013). Multiple site dissimilarity quantifies compositional heterogeneity among several sites, while average pairwise dissimilarity may be misleading. Ecography, 36, 124-128. https://doi. org/10.1111/j.1600-0587.2012.00124.x

Baselga, A., \& Orme, C. D. L. (2012). betapart: An R package for the study of beta diversity. Methods in Ecology and Evolution, 3, 808-812. https://doi.org/10.1111/j.2041-210x.2012.00224.x

Baselga, A., Orme, D., Villeger, S., De Bortoli, J., \& Leprieur, F. (2018). betapart: Partitioning beta diversity into turnover and nestedness components. R package version 1.5.0.

Beisner, B. E., Peres-Neto, P. R., Lindström, E. S., Barnett, A., \& Longhi, M. L. (2006). The role of environmental and spatial processes in structuring lake communities from bacteria to fish. Ecology, 87, 2985-2991. https://doi.org/10.1890/0012-9658(2006)87[2985:troeas]2.0.co;2

Berkes, F., \& Jolly, D. (2002). Adapting to climate change: Social-ecological resilience in a Canadian western Arctic community. Conservation Ecology, 5, 18. https://doi.org/10.5751/es-00342-050218

Brittain, J. E., Gíslason, G. M., Ponomarev, V. I., Bogen, J., Brørs, S., Jensen, A. J., ... Stenina, A. S. (2009). Arctic rivers. In K. Tockner, U. Uehlinger, \& C. T. Robinson (Eds.), Rivers of Europe (pp. 337379). London, UK: Academic Press. https://doi.org/10.1016/ b978-0-12-369449-2.00009-6

Cayuela, L., \& Gotelli, N. J. (2014). rareNMtests: Ecological and biogeographical null model tests for comparing rarefaction curves. $\mathrm{R}$ package version 1.1. https://CRAN.R-project.org/package=rareNMtests

Cayuela, L., Gotelli, N. J., \& Colwell, R. K. (2015). Ecological and biogeographic null hypotheses for comparing rarefaction curves. Ecological Monographs, 85, 437-455. https://doi.org/10.1890/14-1261.1

CEN. (2015). Water quality - sampling of fish with multi-mesh gillnets. European Standard. European Committee for Standardization. Ref. No. EN 14757:2015.

Christiansen, J. S., Reist, J. D., Brown, R. J., Brykov, V. A., Christensen, G., Christoffersen, K., ... Wrona, F. J. (2013). Fishes. In H. Meltofte, A. B. Josefson, \& D. Payer (Eds.), Arctic biodiversity assessment (pp. 192-245). Akureyri, Iceland: Conservation of Arctic Flora and Fauna (CAFF).

Comte, L., Buisson, L., Daufresne, M., \& Grenouillet, G. (2013). Climateinduced changes in the distribution of freshwater fish: Observed and predicted trends. Freshwater Biology, 58, 625-639. https://doi. org/10.1111/fwb.12081

Conservation of Arctic Flora and Fauna (CAFF). (2013). Arctic biodiversity assessment: Report for policy makers. Akureyri, Iceland: Conservation of Arctic Flora and Fauna (CAFF).

Craig, P. C. (1984). Fish use of coastal waters of the Alaskan Beaufort Sea: A review. Transactions of the American Fisheries Society, 113, 265-282. https://doi.org/10.1577/1548-8659(1984)113\&lt;265:fuocwo\&gt;2.0.co;2
Culp, J. M., Goedkoop, W., Lento, J., Christoffersen, K. S., Frenzel, S., Guðbergsson, G., ... Whitman, M. (2012). The Arctic Biodiversity Monitoring Plan. CAFF International Secretariat, CAFF Monitoring Series Report Nr. 7. Akureyri, Iceland: Conservation of Arctic Flora and Fauna (CAFF).

Degerman, E., \& Sers, B. (1992). Fish assemblages in Swedish streams. Nordic Journal of Freshwater Research, 67, 61-71.

Dias, M. S., Oberdorff, T., Hugueny, B., Leprieur, F., Jézéquel, C., Cornu, J.-F., ... Tedesco, P. A. (2014). Global imprint of historical connectivity on freshwater fish biodiversity. Ecology Letters, 17, 1130-1140. https://doi.org/10.1111/ele.12319

Eloranta, A. P., Kahilainen, K. K., Amundsen, P.-A., Knudsen, R., Harrod, C., \& Jones, R. I. (2015). Lake size and fish diversity determine resource use and trophic position of a top predator in high-latitude lakes. Ecology and Evolution, 5, 1664-1675. https://doi.org/10.1002/ ece3.1464

Erkinaro, J., Czorlich, Y., Orell, P., Kuusela, J., Länsman, M., Pulkkinen, H., ... Niemelä, E. (2019). Life history variation across four decades in a diverse population complex of Atlantic salmon in a large subarctic river. Canadian Journal of Fisheries and Aquatic Sciences, 76, 42-55. https://doi.org/10.1139/cjfas-2017-0343

Gotelli, N. J., \& Colwell, R. K. (2001). Quantifying biodiversity: Procedures and pitfalls in the measurement and comparison of species richness. Ecology Letters, 4, 379-391. https://doi. org/10.1046/j.1461-0248.2001.00230.x

Gotelli, N. J., Shimadzu, H., Dornelas, M., McGill, B., Moyes, F., \& Magurran, A. E. (2017). Community-level regulation of temporal trends in biodiversity. Science Advances, 3, e1700315. https://doi. org/10.1126/sciadv.1700315

Griffiths, D. (2006). Pattern and process in the ecological biogeography of European freshwater fish. Journal of Animal Ecology, 75, 734-751. https://doi.org/10.1111/j.1365-2656.2006.01094.x

Griffiths, D. (2010). Pattern and process in the distribution of North American freshwater fish. Biological Journal of the Linnean Society, 100, 46-61. https://doi.org/10.1111/j.1095-8312.2010.01404.x

Griffiths, D. (2015). Connectivity and vagility determine species richness gradients and diversification of freshwater fish in North America and Europe. Biological Journal of the Linnean Society, 116, 773-786. https://doi.org/10.1111/bij.12638

Guerin, G. R., Biffin, E., \& Lowe, A. J. (2013). Spatial modelling of species turnover identifies climate ecotones, climate change tipping points and vulnerable taxonomic groups. Ecography, 36, 1086-1096. https://doi.org/10.1111/j.1600-0587.2013.00215.x

Hayden, B., Harrod, C., Sonninen, E., \& Kahilainen, K. K. (2015). Seasonal depletion of resources intensifies trophic interactions in subarctic freshwater fish communities. Freshwater Biology, 60, 1000-1015.

Hayden, B., Myllykangas, J.-P., Rolls, R. J., \& Kahilainen, K. K. (2017). Climate and productivity shape fish and invertebrate community structure in subarctic lakes. Freshwater Biology, 62, 990-1003. https://doi.org/10.1111/fwb.12919

Heino, J. (2011). A macroecological perspective of diversity patterns in the freshwater realm. Freshwater Biology, 56, 1703-1722. https://doi. org/10.1111/j.1365-2427.2011.02610.x

Henriques-Silva, R., Lindo, Z., \& Peres-Neto, P. R. (2013). A community of metacommunities: Exploring patterns in species distributions across large geographical areas. Ecology, 94, 627-639. https://doi. org/10.1890/12-0683.1

Hershey, A. E., Beaty, S., Fortino, K., Keyse, M., Mou, P. P., O'Brien, W. J., ... Whalen, S. C. (2006). Effect of landscape factors on fish distribution in arctic Alaskan lakes. Freshwater Biology, 51, 39-55. https://doi. org/10.1111/j.1365-2427.2005.01474.x

Hershey, A. E., Gettel, G. M., McDonald, M. E., Miller, M. C., Mooers, H., O'Brien, W. J., ... Schuldt, J. A. (1999). A geomorphic-trophic model for landscape control of Arctic lake food webs. BioScience, 49, 887897. https://doi.org/10.2307/1313648 
Hewitt, G. (2000). The genetic legacy of the Quaternary ice ages. Nature, 405, 907-913. https://doi.org/10.1038/35016000

Hijmans, R. J. (2017). geosphere: Spherical trigonometry. R package version 1.5-7. https://CRAN.R-project.org/package $=$ geosphere

Hillebrand, H., Blasius, B., Borer, E. T., Chase, J. M., Downing, J. A., Eriksson, B. K., ... Ryabov, A. B. (2018). Biodiversity change is uncoupled from species richness trends: Consequences for conservation and monitoring. Journal of Applied Ecology, 55, 169-184. https://doi. org/10.1111/1365-2664.12959

Holmgren, K., \& Appelberg, M. (2000). Size structure of benthic freshwater fish communities in relation to environmental gradients. Journal of Fish Biology, 57, 1312-1330. https://doi. org/10.1111/j.1095-8649.2000.tb00489.x

Hovelsrud, G. K., Poppel, B., van Oort, B., \& Reist, J. D. (2011). Arctic societies, cultures, and peoples in a changing cryosphere. Ambio, 40, 100-110. https://doi.org/10.1007/s13280-011-0219-4

Hu, X. F., Laird, B. D., \& Chan, H. M. (2017). Mercury diminishes the cardiovascular protective effect of omega-3 polyunsaturated fatty acids in the modern diet of Inuit in Canada. Environmental Research, 152, 470-477. https://doi.org/10.1016/j.envres.2016.06.001

Hugueny, B., Oberdorff, T., \& Tedescco, P. A. (2010). Community ecology of river fishes: A large-scale perspective. American Fisheries Society Symposium, 73, 29-62.

Huntington, H. P., Boyle, M., Flowers, G. E., Weatherly, J. W., Hamilton, L. C., Hinzman, L., ... Overpeck, J. (2007). The influence of human activity in the Arctic on climate and climate impacts. Climatic Change, 82, 77-92. https://doi.org/10.1007/s10584-006-9162-y

Koleff, P., Gaston, K. J., \& Lennon, J. K. (2003). Measuring beta diversity for presence-absence data. Journal of Animal Ecology, 72, 367-382. https://doi.org/10.1046/j.1365-2656.2003.00710.x

Koljonen, M.-L., Jansson, H., Paaver, T., Vasin, O., \& Koskiniemi, J. (1999). Phylogenetic lineages and differentiation patterns of Atlantic salmon (Salmo salar) in the Baltic Sea with management implications. Canadian Journal of Fisheries and Aquatic Sciences, 56, 1766-1780. https://doi.org/10.1139/f99-104

Kraft, N. J. B., Comita, L. S., Chase, J. M., Sanders, N. J., Swenson, N. G., Crist, T. O., ... Myers, J. A. (2011). Disentangling the drivers of $\beta$ diversity along latitudinal and elevational gradients. Science, 333, 1755-1758. https://doi.org/10.1126/science.1208584

Laske, S. M., Haynes, T. B., Rosenberger, A. E., Koch, J. C., Wipfli, M. S., Whitman, M., \& Zimmerman, C. E. (2016). Surface water connectivity drives richness and composition of Arctic lake fish assemblages. Freshwater Biology, 61, 1090-1104. https://doi.org/10.1111/ fwb.12769

Legendre, P., Borcard, D., \& Peres-Neto, P. R. (2005). Analyzing beta diversity: Partitioning the spatial variation of community composition data. Ecological Monographs, 75, 435-450. https://doi. org/10.1890/05-0549

Lehner, B., \& Grill, G. (2013). Global river hydrology and network routing: Baseline data and new approaches to study the world's large river systems. Hydrological Processes, 27, 2171-2186. https://doi. org/10.1002/hyp.9740

Lennon, J. J., Koleff, P., Greenwood, J. J. D., \& Gaston, K. (2001). The geographical structure of British bird distributions: Diversity, spatial turnover and scale. Journal of Animal Ecology, 70, 966-979. https:// doi.org/10.1046/j.0021-8790.2001.00563.x

Leprieur, F., Tedesco, P. A., Hugueny, B., Beauchard, O., Dürr, H. H., Brosse, S., \& Oberdorff, T. (2011). Partitioning global patterns of freshwater fish beta diversity reveals contrasting signatures of past climate changes. Ecology Letters, 14, 325-334. https://doi. org/10.1111/j.1461-0248.2011.01589.x

Lucek, K., Kristjánsson, B. K., Skúlason, S., \& Seehausen, O. (2016). Ecosystem size matters: The dimensionality of intralacustrine diversification in Icelandic stickleback is predicted by lake size. Ecology and Evolution, 15, 5256-5272. https://doi.org/10.1002/ece3.2239
Magnuson, J. J., Tonn, W. M., Banerjee, A., Toivonen, J., Sanchez, O., \& Rask, M. (1998). Isolation vs. extinction in the assembly of fishes in small northern lakes. Ecology, 79, 2941-2956. https://doi. org/10.1890/0012-9658(1998)079[2941:iveita]2.0.co;2

Mangerud, J., Jakobsson, M., Alexanderson, H., Astakhov, V., Clarke, G. K. C., Henriksen, M., ... Svendsen, J. I. (2004). Ice-dammed lakes and rerouting of the drainage of northern Eurasia during the last glaciation. Quaternary Science Reviews, 23, 1313-1332. https://doi. org/10.1016/j.quascirev.2003.12.009

Mecklenburg, C. W., Mecklenburg, T. A., \& Thorsteinson, L. K. (2002). Fishes of Alaska. Bethesda, Maryland: American Fisheries Society.

Meltofte, H. (Ed.). (2013). Arctic biodiversity assessment, status and trends in Arctic biodiversity. Akureyri, Iceland: Conservation of Arctic Flora and Fauna.

Muus, B. J., \& Dahlström, P. (1993). Freshwater fish of Europe: Biology, catch, economic importance. Munich, Germany: BLV Verlagsgesellschaft $\mathrm{mbH}$.

Nesbø, C. L., Fossheim, T., Vøllestad, L. A., \& Jakobsen, K. S. (1999). Genetic divergence and phylogenetic relationships among European perch (Perca fluviatilis) populations reflect glacial refugia and postglacial colonization. Molecular Ecology, 8, 1387-1404. https://doi. org/10.1046/j.1365-294x.1999.00699.x

Nielsen, A. B., Hamerlik, L., \& Christoffersen, K. (2012). Three-spined stickleback Gasterosteuas aculeatus recorded for the first time at Zackenberg - short description and comparative analysis with char food biology. In L. M. Jensen (Ed.), Zackenberg Ecological Research Operations, 17th Annual report, 2011 (Pp 92-95). Denmark: DCE Danish Centre for Environment and Energy, Aarhus University.

Novikov, G. G., Politov, D. V., Makhrov, A. A., Malinina, T. V., Afanasiev, K. I., \& Fernholm, B. (2000). Freshwater and estuarine fishes of the Russian Arctic coast (the Swedish-Russian Expedition 'Tundra Ecology-94'). Journal of Fish Biology, 57(Supplement A), 158-162.

Oksanen, J., Blanchet, F. G., Friendly, M., Kindt, R., Legendre, P., McGlinn, D., ... Wagner, H. (2018). vegan: Community ecology package. R package version 2.4-6. https://CRAN.R-project.org/package=vegan

Olson, D. M., Dinerstein, E., Wikramanayake, E. D., Burgess, N. D., Powell, G. V. N., Underwood, E. C., ... Kassem, K. R. (2001). Terrestrial ecoregions of the world: A new map of life on Earth. BioScience, 51, 933-938. https://doi.org/10.1641/0006-3568(2001)051[0933:teotwa]2.0.co;2

Østbye, K., Bernatchez, L., Næsje, T. F., Himberg, K.-J. M., \& Hindar, K. (2005). Evolutionary history of the European whitefish Coregonus lavaretus (L.) species complex as inferred from mtDNA phylogeography and gill-raker numbers. Molecular Ecology, 14, 4371-4387.

Oswood, M. W., Reynolds, J. B., Irons, J. G., \& Milner, A. M. (2000). Distributions of freshwater fishes in ecoregions and hydroregions of Alaska. Journal of the North American Benthological Society, 19, 405418. https://doi.org/10.2307/1468103

Poff, N. L. (1997). Landscape filters and species traits: Towards mechanistic understanding and prediction in stream ecology. Journal of the North American Benthological Society, 16, 391-409. https://doi. org/10.2307/1468026

Ponomarev, V. I. (2017). Fishes of lakes of the western slopes of the prepolar and polar Urals. Proceedings of the Komi Science Centre, Ural Branch of the Russian Academy of Sciences, 2, 16-29.

Power, M., Reist, J. D., \& Dempson, J. B. (2008). Fish in high latitude Arctic lakes. In W. F. Vincent, \& J. Laybourn-Parrry (Eds.), Polar lakes and rivers: Limnology of Arctic and Antarctic aquatic ecosystems. Oxford, UK: Oxford University Press.

Rautio, M., Dufresne, F., Laurion, I., Bonilla, S., Vincent, W. F., \& Christoffersen, K. S. (2011). Shallow freshwater ecosystems of the circumpolar Arctic. Ecoscience, 18, 204-222. https://doi. org/10.2980/18-3-3463

Reist, J. D., Wrona, F. J., Prowse, T. D., Power, M., Dempson, J. B., Beamish, R. J., ... Sawatzky, C. D. (2006). General effects of climate 
change on Arctic fishes and fish populations. Ambio, 35, 370-380. https://doi.org/10.1579/0044-7447(2006)35[370:geocco]2.0.co;2

Rolls, R. J., Heino, J., Ryder, D. S., Chessman, B. C., Growns, I. O., Thompson, R. M., \& Gido, K. B. (2018). Scaling biodiversity responses to hydrological regimes. Biological Reviews, 93, 971-995. https://doi. org/10.1111/brv.12381

Romanov, V. I., Zuykova, E. I., \& Bochkarev, N. A. (2016). Morphological and ecological differentiation of sympatric whitefish species of the genus Coregonus from Lake Taymyr. Contemporary Problems of Ecology, 9, 290-296. https://doi.org/10.1134/s1995425516030136

Sala, O. E., Chapin, F. S., Armesto, J. J., Berlow, E., Bloomfield, J., Dirzo, R., ... Wall, D. H. (2000). Global biodiversity scenarios for the year 2100. Science, 287, 1770-1774. https://doi.org/10.1126/scien ce.287.5459.1770

Schindler, D. W., \& Smol, J. P. (2006). Cumulative effects of climate warming and other human activities on freshwaters of Arctic and subarctic North America. Ambio, 35, 160-168. https://doi. org/10.1579/0044-7447(2006)35[160:ceocwa]2.0.co;2

Schleuter, D., Daufresne, M., Veslot, J., Mason, N. W. H., Lanoiselée, C., Brosse, S., ... Argillier, C. (2012). Geographic isolation and climate govern the functional diversity of native fish communities in European drainage basins. Global Ecology and Biogeography, 21, 1083-1095. https://doi.org/10.1111/j.1466-8238.2012.00763.x

Scott, W. B., \& Crossman, E. J. (1973). Freshwater Fishes of Canada. Bulletin 184. Ottawa: Fisheries Research Board of Canada.

Shuter, B. J., Finstad, A. G., Helland, I. P., Zweimüller, I., \& Hölker, F. (2012). The role of winter phenology in shaping the ecology of freshwater fish and their sensitivities to climate change. Aquatic Sciences, 74, 637-657. https://doi.org/10.1007/s00027-012-0274-3

Siwertsson, A., Knudsen, R., Kahilainen, K. K., Præbel, K., Primicerio, R., \& Amundsen, P.-A. (2010). Sympatric diversification as influenced by ecological opportunity and historical contingency in a young species lineage of whitefish. Evolutionary Ecology Research, 12, 929-947.

Skúlason, S., Parsons, K. J., Svanbäck, R., Räsänen, K., Ferguson, M. M., Adams, C. E., ... Snorrason, S. S. (2019). A way forward with eco evo devo: an extended theory of resource polymorphism with postglacial fishes as model systems. Biological Reviews, 94, 1786-1808.

Socolar, J. B., Gilroy, J. J., Kunin, W. E., \& Edwards, D. P. (2016). How should beta-diversity inform biodiversity conservation? Trends in Ecology \& Evolution, 31, 67-80. https://doi.org/10.1016/j.tree.2015.11.005

Soininen, J., McDonald, R., \& Hillebrand, H. (2007). The distance decay of similarity in ecological communities. Ecography, 30, 3-12. https:// doi.org/10.1111/j.0906-7590.2007.04817.x

Stendera, S., Adrian, R., Bonada, N., Cañedo-Argüelles, M., Hugueny, B., Januschke, K., ... Hering, D. (2012). Drivers and stressors of freshwater biodiversity patterns across different ecosystems and scales: A review. Hydrobiologia, 696, 1-28. https://doi.org/10.1007/ s10750-012-1183-0

Svenning, M.-A., Aas, M., \& Borgstrøm, R. (2015). First records of threespined stickleback Gasterosteus aculeatus in Svalbard freshwaters: An effect of climate change? Polar Biology, 38, 1937-1940. https://doi. org/10.1007/s00300-015-1752-6
Taylor, E. B. (1999). Species pairs of north temperate freshwater fishes: Evolution, taxonomy, and conservation. Reviews in Fish Biology and Fisheries, 9, 299-324. https://doi.org/10.1023/a:1008955229420

Thomas, S. M., Harrod, C., Hayden, B., Malinen, T., \& Kahilainen, K. K. (2017). Ecological speciation in a generalist consumer expands the trophic niche of a dominant predator. Scientific Reports, 7, 8765. https://doi.org/10.1038/s41598-017-08263-9

Tonn, W. M. (1990). Climate change and fish communities: A conceptual framework. Transactions of the American Fisheries Society, 119, 337352. https://doi.org/10.1577/1548-8659(1990)119\&lt;0337:ccafc a\&gt;2.3.co;2

Tonn, W. M., Magnuson, J. J., Rask, M., \& Toivonen, J. (1990). Intercontinental comparison of small-lake fish assemblages: The balance between local and regional processes. The American Naturalist, 136, 345-375. https://doi.org/10.1086/285102

Whittaker, R. H. (1972). Evolution and measurement of species diversity. Taxon, 21, 213-251. https://doi.org/10.2307/1218190

Woods, P. J., Skúlason, S., Snorrason, S. S., Kristjánsson, B. K., Malmquist, H. J., \& Quinn, T. P. (2012). Intraspecific diversity in Arctic charr, Salvelinus alpinus, in Iceland: II. Which environmental factors influence resource polymorphism in lakes? Evolutionary Ecology Research, 14, 993-1013.

Wrona, F. J., Prowse, T. J., Reist, J. D., Hobbie, J. E., Lévesque, L. M. J., \& Vincent, W. F. (2006). Climate change effects on aquatic biota, ecosystem structure and function. Ambio, 35, 359-369. https://doi. org/10.1579/0044-7447(2006)35[359:cceoab]2.0.co;2

Wrona, F. J., Reist, J. D., Amundsen, P.-A., Chambers, P. A., Christoffersen, K., Culp, J. M., ... Zavalko, S. (2013). Freshwater Ecosystems. In H. Meltofte, A. B. Josefson, \& D. Payer (Eds.), Arctic Biodiversity Assessment (pp. 443-485). Akureyri, Iceland: Conservation of Arctic Flora and Fauna (CAFF).

\section{SUPPORTING INFORMATION}

Additional supporting information may be found online in the Supporting Information section.

How to cite this article: Laske SM, Amundsen P-A, Christoffersen KS, et al. Circumpolar patterns of Arctic freshwater fish biodiversity: A baseline for monitoring. Freshw Biol. 2022;67:176-193. https://doi.org/10.1111/fwb.13405 